\title{
Las retribuciones complementarias del personal de las Fuerzas Armadas ${ }^{1}$
}

\section{Supplementary remunerations for Armed Forces personnel}

\author{
Ana $M^{a}$ Moreno Márquez \\ Profesora Contratada Doctora de Derecho del Trabajo \\ y de la Seguridad Social \\ Acreditada como Profesora Titular de Universidad \\ Departamento de Derecho Social e Internacional Privado, \\ Universidad Carlos III de Madrid \\ SUMARIO: I. LA NEGESARIA ADAPTACIÓN DEL SISTEMA RE- \\ TRIBUTIVO DE LOS FUNCIONARIOS CIVILES DE LA ADMINIS- \\ TRACIÓN GENERAL DEL ESTADO COMO PUNTO DE PARTIDA. \\ II. EL COMPLEMENTO DE EMPLEO. 1. La diferencia con respecto \\ al complemento de destino y su fundamento. 2. El empleo ostentado como \\ elemento uniformador en cuanto a la atribución del complemento de em- \\ pleo y sus posibles excepciones. III. EL COMPLEMENTO ESPECÍFICO. \\ PROYEGGIÓN DEL EMPLEO EN SU REGULAGIÓN Y EN SU APLI- \\ CACIÓN PRÁCTICA. 1. El componente general del complemento especí- \\ fico y su percepción en función del empleo. 2. El componente singular del \\ complemento específico. A. Vinculación al puesto de trabajo. B. ¿Hasta qué \\ punto tiene relevancia el empleo en la práctica? $\mathrm{C}$. El efectivo desempeño \\ del puesto. D. La valoración de los factores que determinan la asignación \\ del componente singular. IV. EL COMPLEMENTO DE DEDICAGIÓN \\ ESPECIAL. 1. El especial rendimiento, la actividad extraordinaria o la ini- \\ ciativa y su determinación en el ámbito militar. 2. El carácter subjetivo del \\ complemento de dedicación especial y su atribución. 3. La incidencia de \\ determinados factores en su percepción y/o su cuantía. V. LA GRATIFI-
}

\footnotetext{
Este trabajo se ha llevado a cabo en el marco del Proyecto de Investigación "El salario en el contexto de la globalización, las nuevas formas de organización empresarial y la economía digital" (RTI2018096674-B-C22).

Recibido: 03/10/2019

Acrptado: 08/11/2019
} 
CACIÓN POR SERVIGIOS EXTRAORDINARIOS. 1. La necesidad de que los servicios se realicen fuera de la jornada normal de trabajo. 2. Los servicios extraordinarios como actividades no exclusivamente militares. VI. VALORACIONES FINALES. VII. BIBLIOGRAFÍA.

RESUMEN: A pesar de que el sistema retributivo del personal de las Fuerzas Armadas es el previsto para los funcionarios civiles de la Administración General del Estado, con determinadas adaptaciones, lo cierto es que existen claras diferencias en el tratamiento de ambos colectivos en esta materia, en particular, con respecto a los complementos retributivos. En el presente trabajo se analizan de forma detallada estos complementos, en qué términos se han producido esas adaptaciones y, sobre todo, los problemas que se han venido planteando en la práctica, junto a las consecuencias derivadas de los mismos y las posibles soluciones; unos problemas que van más allá de su cuantía, y que, a pesar del interés que han venido suscitando para el colectivo, han sido escasamente estudiados.

PALABRAS CLAVE: adaptación normativa, retribuciones complementarias, Fuerzas Armadas.

ABSTRACT: Although the remuneration system for Armed Forces personnel is intended for civil servants of the General Administration of the State, with certain adaptations, the fact is that there are clear differences in the treatment of both groups on this subject, in particular with regard to supplementary remunerations. This paper analyses in detail these remunerations, in what terms these adaptations have occurred and, above all, the problems that have been raised in practice, together with the consequences arising therefrom and the possible solutions; problems that go beyond their amount, and which, despite the interest they have been arousing for the collective, have been poorly studied.

KEY WORDS: normative adaptation, supplementary remunerations, Armed Forces.

\section{LA NEGESARIA ADAPTACIÓN DEL SISTEMA RETRIBUTIVO DE LOS FUNCIONARIOS GIVILES DE LA ADMINISTRACIÓN GENERAL DEL ESTADO GOMO PUNTO DE PARTIDA}

Si bien es cierto que el art. 25 de la Ley Orgánica 9/2011, de 27 de julio, de derechos y deberes de los miembros de las Fuerzas Armadas (LOFFAA) ${ }^{2}$, señala que el sistema retributivo de este colectivo será el de los funcionarios civiles de la

$2 \quad$ BOE de 28 de julio de 2011. 
Administración General del Estado, también lo es que establece su adaptación "a las características de las Fuerzas Armadas, a las peculiaridades de la carrera militar y a la singularidad de los cometidos y funciones que tienen asignados"; tal y como ya se contemplaba en el art. 152 de la Ley 17/1999, de 18 de mayo, de régimen del personal de las Fuerzas Armadas (LRPFFAA) . Además, por lo que aquí interesa, con respecto a dicha adaptación, el citado art. 25 de la LOFFAA hace referencia a las retribuciones complementarias para indicar que por medio de las mismas "se atenderán las características del ejercicio de la profesión militar, especialmente la responsabilidad, los diferentes grados de disponibilidad, el horario, la preparación técnica y las singularidades de determinados cometidos"; del mismo modo que ya se establecía en el art. 152 de la LRPFFAA, si bien este último no mencionaba aspectos como la disponibilidad y el horario, aunque, como se verá, se han venido considerando a la hora de proceder a la referida adaptación. En este sentido, hay que tener en cuenta que el personal de las Fuerzas Armadas tiene encomendada la Defensa nacional, función que se contempla en el art. 8 de la Constitución Española (CE) como el deber de "garantizar la soberanía e independencia de España, defender su integridad territorial y el ordenamiento constitucional" y que, precisamente, es "la razón de ser de los Ejércitos", es decir, se trata de una función estatal que se materializa a través de las citadas Fuerzas Armadas. Una función, por tanto, que, a su vez, precisa "una específica forma de organización y un régimen jurídico singular" ${ }^{5}$, esto es, una organización fuertemente jerarquizada, en la que predomina la disciplina y la unidad (arts. 7 a 10 del Real Decreto 96/2009, de 6 de febrero, por el que se aprueban las Reales Ordenanzas para las Fuerzas Armadas, en adelante, RDRROO) ${ }^{6}$, dirigida al cumplimiento de la misma, y un régimen jurídico específico en el que se contemplan adaptaciones y limitaciones de derechos que obedecen a la necesidad de preservar dicha función (art. 12 del RDRROO).

De ahí que tanto en el art. 152 de la LRPFFAA, como en el art. 25 de la LOFFAA se haya venido haciendo referencia a la necesaria adaptación del sistema retributivo de los funcionarios civiles de la Administración General del Estado. Adaptación que en la actualidad se refleja en su regulación en el Real Decreto 1314/2005, de 4 de noviembre, por el que se aprueba el Reglamento de retribuciones del personal de las Fuerzas Armadas (RD 1314/2005)ㄱ, que derogó el Real Decreto 662/2001, de 21 de junio, por el que se aprueba el Reglamento de retribuciones de dicho personal

\footnotetext{
3 BOE de 19 de mayo de 1999.

4 Tal y como se señalaba en el art. 3 la Ley 85/1987, de 28 de diciembre, de Reales Ordenanzas de las Fuerzas Armadas (BOE de 12 de enero de 1979), actualmente derogada.

5 Cfr. STC 107/1986, de 24 de junio.

6 BOE de 7 de febrero de 2009.

7 BOE de 5 de noviembre de 2005.
} 
(RD 662/2001) ${ }^{8}$, en el que precisamente se puede apreciar cómo, de acuerdo con lo señalado, el legislador ya ha tenido en cuenta para ello diferentes aspectos tales como la disponibilidad permanente de los miembros de las Fuerzas Armadas para el servicio; el hecho de que, en ocasiones, realicen su labor en condiciones de penosidad física y riesgo personal; su estructura fuertemente jerarquizada y la progresión en la carrera militar, en concreto, el empleo, la responsabilidad y las singularidades de ciertos cometidos.

Como se puede comprobar, se trata de una regulación en la que no se establece un modelo retributivo totalmente alternativo, por el contrario, se puede observar cómo las retribuciones de los militares han venido siguiendo la misma estructura que la prevista para los funcionarios civiles de la Administración General del Estado 9 . Ahora bien, tal y como ha señalado el Tribunal Supremo (TS), también se puede constatar cómo en la función pública militar "las retribuciones giran fundamentalmente en torno al empleo militar que se ostenta, mientras que en la función pública civil las retribuciones se determinan en mucha mayor medida por el puesto de trabajo que se desempeña"10; lo que implica que, a pesar de que, como se ha indicado, las retribuciones siguen esa misma estructura, en realidad no existe una identidad entre el sistema retributivo militar y el civil.

Así, el legislador distingue entre retribuciones básicas, esto es, sueldo, trienios y pagas extraordinarias, para las que existe una coincidencia con respecto a las previstas para los citados funcionarios civiles, con alguna particularidad, ya que, a efectos retributivos, se parte de los empleos militares y se establecen unas equivalencias con respecto a los funcionarios civiles (art. 2 del RD 1314/2005); y retribuciones complementarias. Pues bien, es en cuanto a estas últimas en las que verdaderamente se puede apreciar que el legislador ha realizado la citada adaptación y, por tanto, ha establecido unas claras diferencias que se reflejan en la propia denominación de algunos de los complementos retributivos. En concreto, toma como referentes los complementos de destino y de productividad, para contemplar en este caso, respectivamente, el complemento de empleo y el complemento de dedicación especial; no modifica la denominación del complemento específico, pero, como se verá, en su regulación se pueden detectar singularidades para este colectivo, como el hecho de

8 BOE de 23 de junio de 2001. Vid. SALVADOR CENTELLES, V., "La reforma del sistema retributivo del personal de las Fuerzas Armadas", en Presupuesto y Gasto Público, núm. 41 (2005), pp. 333-348.

9 Con respecto a esta estructura, vid. ORTUÑO NAVALÓN, M.C. y MANZANA LAGUARDA, R.S., Las retribuciones de los empleados públicos. Estatuto Básico del Empleado Público, Tirant lo Blanch, Valencia, 2008; y LORENZO DE MEMBIELA, J.B., Retribuciones de los Funcionarios Públicos, Aranzadi Thomson Reuters, Cizur Menor, 2010.

10 Cfr. SSTS (Sala de lo Contencioso-administrativo) de 20 de junio de 2005 (rec. 46/2003) y de 25 de febrero de 2002 (rec. 1619/2000). 
que en el mismo se integre un componente general y un componente singular, y, en particular, que se ponga de manifiesto la diferente caracterización jurídica de la carrera profesional con respecto al ámbito civil. En general, como se verá, se puede afirmar que la adaptación va más allá de la modificación de su denominación o de la estructura del complemento en su caso, ya que obedece a un fundamento y a una lógica que difieren, en mayor o menor medida, de aquellos de los que se parte en el ámbito civil.

\section{EL COMPLEMENTO DE EMPLEO}

Tal y como se ha indicado, el denominado complemento de empleo en el ámbito militar se corresponde en el civil con el complemento de destino (art. 3.1 del RD 1314/2005). En este sentido, en la práctica, se ha cuestionado si la referencia que hace el legislador en dicho artículo a la correspondencia entre uno y otro complemento conlleva su equiparación, o, por el contrario, no es posible interpretarla en esos términos.

\section{La diferencia con respecto al complemento de destino y su fundamento}

Tanto el complemento de destino como el de empleo forman parte de las retribuciones complementarias. En el ámbito civil, como señalaba el art. 23.3 a) de la Ley 30/1984, de 2 de agosto, de medidas para la reforma de la Función Pública $(\mathrm{LMRFP})^{11}$, el complemento de destino se contemplaba como el "correspondiente al nivel de puesto que se desempeñe" y, en la actualidad, de acuerdo con lo establecido en el art. 24 a) del Real Decreto Legislativo 5/2015, de 30 de octubre, por el que se aprueba el texto refundido de la Ley del Estatuto Básico del Empleado Público $(\mathrm{EBEP})^{12}$, aunque el legislador no hace una referencia expresa al mismo, está vinculado a "la progresión alcanzada por el funcionario dentro del sistema de carrera administrativa"13, mientras que en el ámbito militar para proceder a la adaptación a la que se ha hecho referencia se ha partido precisamente de la estructura jerarquizada de las Fuerzas Armadas y la correspondiente responsabilidad; unos criterios a los que tradicionalmente se ha venido recurriendo ${ }^{14}$. De modo que, de acuerdo con lo establecido en el art. 3.2 del RD 1314/2005, este complemento retribuye "la distinta

\footnotetext{
11 BOE de 3 de agosto de 1984.

12 BOE de 31 de octubre de 2015.

13 Con respecto al complemento de destino, vid. ORTUÑO NAVALÓN, M.C. y MANZANA LAGUARDA, R.S. (2008: 62-73).

14 Vid. art. 5.2 del RD 662/2001 y la regulación vigente establecida en el art. 3.2 del RD $1314 / 2005$.
} 
responsabilidad según el empleo militar que se tenga, derivada del ejercicio de la profesión militar" y responde a la citada estructura; si bien "los empleos de teniente y alférez" tienen el mismo complemento. Desde este punto de vista, se parte de la distribución y las cuantías previstas para los funcionarios civiles para trasladarla a la normativa militar, por lo que se aprecia esa correspondencia que señala el legislador, pero también se produce una adaptación.

En concreto, en el ámbito militar, para fijar su importe se parte de los establecido en el ámbito civil para los niveles de complemento de destino asignados a los puestos de trabajo desempeñados por los funcionarios del Estado, de modo que, como se puede comprobar en el anexo II del RD 1314/2005, cada empleo tiene un nivel (excepto algunos empleos superiores y los que tienen el mismo nivel, como sucede con el empleo de alférez y teniente). Así, al empleo de coronel se le asigna el nivel 29 y a partir del mismo va descendiendo el nivel a la vez que se reduce la retribución por este concepto hasta llegar al empleo de soldado/marinero. Pues bien, aunque pueda parecer, teniendo en cuenta esa distribución por niveles y el correspondiente importe, que se aprecia una cierta identidad, en realidad no es así. El complemento de destino en el ámbito de la Administración civil está vinculado al puesto de trabajo, de modo que tiene carácter objetivo ${ }^{15}$, mientras que en el ámbito militar el complemento de empleo se encuentra ligado a la graduación jerárquica del militar, esto es, al empleo, al margen del puesto que ocupe, y, desde este punto de vista, tiene carácter personal o subjetivo en el sentido de que dependerá de la posición que tenga el sujeto en la citada jerarquía a partir de los ascensos que haya obtenido; sin que se tengan en cuenta otras circunstancias subjetivas que puedan concurrir, como pueden ser la capacitación del sujeto, su formación, su preparación técnica, etc; u otras que pueden tener carácter objetivo, como ocurre, como se ha indicado, con el concreto puesto, pero que se vinculan a otros complementos. Por tanto, aunque la distribución sea similar, el fundamento en cada caso es diferente. Mientras que para determinar el complemento de destino en el ámbito civil se tiene en cuenta el nivel del puesto de trabajo desempeñado, o consolidado por haber desempeñado otros puestos anteriores, en el caso del complemento de empleo, para los militares se concreta en función del empleo alcanzado en el desarrollo de su carrera militar ${ }^{16}$.

Además, en relación con lo señalado, hay que considerar que en el ámbito civil habitualmente existen puestos de trabajo que se adscriben para funcionarios de diferentes grupos, lo que ha conllevado una superposición de los distintos niveles del

15 Vid. CASTILLO BLANCO, F.A., El sistema retributivo en la función pública española, Marcial Pons, Madrid, 2002, p. 188.

16 Vid. SSTSJ de Madrid (Sala de lo Contencioso-administrativo) de 9 de mayo de 2019 (rec. 25/2017), de 16 de mayo de 2018 (rec. 635/2016), y de 17 de octubre de 2017 (rec. 523/2016). 
complemento de destino que pueden recibir funcionarios de diferentes grupos ${ }^{17}$; algo que, salvo en el caso del empleo de alférez y el de teniente, no ocurre en el ámbito militar ya que se diferencian los niveles por empleos en función de una relación de carácter jerárquico. Lo que obedece al carácter personal del complemento de empleo que, como se ha indicado, se percibe teniendo en cuenta el empleo alcanzado y con independencia del puesto de trabajo. En todo caso, por lo que aquí interesa, a la vista de lo señalado, la correspondencia entre el complemento de empleo y el complemento de destino no debe interpretarse como equiparación o equivalencia entre uno y otro concepto retributivo ${ }^{18}$, ya sea en términos conceptuales o normativos ${ }^{19}$.

\section{El empleo ostentado como elemento uniformador en cuanto a la atribución del complemento de empleo y sus posibles excepciones}

Como se ha indicado, el complemento de empleo en realidad está vinculado a la responsabilidad según el empleo militar alcanzado por el sujeto, aun así es importante analizar si caben excepciones al respecto teniendo en cuenta otros factores. Pues bien, como regla general, a igualdad de empleo no es posible atribuir un complemento de empleo distinto, con independencia de las características personales o del puesto; distinto por el hecho de que no existe una uniformidad desde el punto de vista de la cuantía, sino que, por el contrario, se establecen claras diferencias teniendo en cuenta el concreto empleo obtenido, con la excepción señalada para el empleo de alférez y teniente, de modo que el complemento de empleo será más o menos elevado que el que pueda percibir otro militar si se considera la específica relación jerárquica que se pone de manifiesto entre empleos. De esta forma, el complemento opera en los mismos términos, aunque no todos los miembros de la Fuerzas Armadas orienten su labor a las mismas funciones, ni tengan la misma especialización técnica, es decir, en este sentido actúa como un elemento uniformador a partir del concreto status del sujeto en la organización, ya que estos aspectos no influyen a la hora de determinarlo ${ }^{20}$.

17 Vid. SSTSJ de Madrid (Sala de lo Contencioso-administrativo) de 9 de mayo de 2019 (rec. 25/2017), de 16 de mayo de 2018 (rec. 635/2016), y de 17 de octubre de 2017 (rec. 523/2016): "la existencia de puestos de trabajo adscritos indistintamente para funcionarios de diferentes grupos se ha traducido en una superposición de los niveles del complemento de destino que pueden percibir funcionarios de grupos diferentes (de 22 a 30 en grupos A; de 18 a 26 en grupo B, de 14 a 22 en grupo C y de 12 a 18 en grupo D)".

18 STSJ de Andalucía, Granada, (Sala de lo Contencioso-administrativo) de 20 de febrero de 2012 (rec. 1659/2007).

19 STSJ de Madrid (Sala de lo Contencioso-administrativo) de 17 de octubre de 2017 (rec. $523 / 2016)$.

20 Vid. BAÑÓN MARTÍNEZ, R., "La racionalidad de las políticas de remuneraciones y el diseño de la organización militar española”, en Revista Internacional de Sociología, núm. 43 (1985), p. 291. 
No obstante, hay que tener en cuenta que en algunos casos el militar puede ocupar una vacante que no está vinculada a un único empleo, sino que podría ser cubierta, indistintamente, por personal de diferentes empleos, como, por ejemplo, en el caso de un sargento primero que ocupa una vacante que es posible cubrir tanto por sujetos con este empleo como por subtenientes, brigadas o sargentos, es decir, por suboficiales, por lo que cabría cuestionarse qué complemento de empleo debe percibir, ya que, no todos tienen el mismo nivel, sino que el empleo de subteniente se sitúa en el nivel 22 y va descendiendo, respectivamente, hasta llegar al nivel 19 para el sargento, atribuyéndose el nivel 20 al sargento primero y el 21 al brigada; lo que es importante, puesto que la retribución que perciben los sujetos en cada caso también disminuye a medida que se sitúan en un lugar inferior en la jerarquía militar, descendiendo así el nivel. En este sentido, podría plantearse si el sujeto debe percibir el complemento de empleo que corresponde al empleo superior, en este supuesto la que recibiría como subteniente, o al inferior, o a uno de los intermedios como es brigada que sería inferior al del sujeto, o la prevista para su empleo, o incluso podría plantearse si debería percibir la media de las diferentes cantidades prevista para los distintos empleos a los que se ha hecho referencia. Pues bien, en la práctica, es posible comprobar cómo, en algunos casos, el militar reclama la cuantía correspondiente al empleo superior de los que pueden ostentarse al efecto; lo que no se ha admitido y tiene sentido si se considera que, en realidad, el complemento de empleo no se encuentra vinculado a la vacante o al puesto de trabajo ocupado por el militar, sino que está ligado al empleo efectivamente ostentado ${ }^{21}$. De este modo, en el supuesto indicado, no cabe reclamar la cuantía correspondiente a este complemento para el citado empleo superior, sino que debe percibir el complemento de empleo previsto para sargento primero.

En relación con lo señalado, también hay que considerar que en el capítulo IV del RD 1314/2005, se hace referencia a las retribuciones e indemnizaciones en casos particulares, y, por lo que aquí interesa, se ha planteado esta cuestión para los miembros de las Fuerzas Armadas que ocupen puestos de trabajo incluidos en las relaciones de puestos de trabajo del Ministerio de Defensa y sus organismos autónomos. Pues bien, el art. 11 del RD 1314/2005 establece que recibirán las retribuciones complementarias asignadas al puesto que desempeñen. De este modo, aunque del art. 3.2 del RD 1314/2005 se pueda extraer que el complemento de empleo está vinculado al empleo que ostente el sujeto dentro de la jerarquía militar, y no al puesto de trabajo que pueda desempeñar de forma efectiva, cuando un militar ejerza las funciones correspondientes a un puesto de trabajo incluido en las citadas relaciones de puestos de

21 Vid. SSTSJ de Madrid (Sala de lo Contencioso-administrativo) de 17 de julio de 2008 (rec. $621 / 2005,622 / 2005,685 / 2005)$ y STSJ de Andalucía (Sala de lo Contencioso-administrativo) de 20 de febrero de 2012 (rec. 1659/2007). 
trabajo del Ministerio de Defensa y sus organismos autónomos, distinto del empleo que ostente, se le debe reconocer el complemento de empleo asignado a ese puesto de trabajo, ya que forma parte de las retribuciones complementarias señaladas ${ }^{22}$. No obstante, puede ocurrir que el importe que corresponda al nivel del complemento de destino del puesto sea inferior a la cuantía prevista para el complemento de empleo asignado a su empleo, pues bien, en ese caso, tal y como establece el art. 11 del RD 1314/2005, recibirá la que se contemple para este último.

\section{EL COMPLEMENTO ESPECÍFICO. PROYECGIÓN DEL EM- PLEO EN SU REGULACIÓN Y EN SU APLICACIÓN PRÁGTICA}

En la actualidad, el legislador al regular las retribuciones complementarias en el EBEP no menciona expresamente el complemento específico, si bien es posible constatar cómo reproduce, en mayor o menor medida, lo establecido en el art. 23.3.b) de la LMRFP, en el que se definía como un complemento "destinado a retribuir las condiciones particulares de algunos puestos de trabajo en atención a su especial dificultad técnica, dedicación, responsabilidad, incompatibilidad, peligrosidad o penosidad". En concreto, el art. 24.b) del EBEP hace referencia a la mayor parte de esos factores, de modo que lo vincula a una "especial dificultad técnica, dedicación, incompatibilidad exigible para el desempeño de determinados puestos de trabajo", si bien ya no menciona aspectos como la peligrosidad o la penosidad que se contemplan en la LMRFP, sino que opta por una fórmula mucho más amplia en la que pueden incluirse estos últimos factores, en concreto, hace referencia a "las condiciones en que se desarrolla el trabajo”. En todo caso, como se puede comprobar, la percepción de este complemento no se encuentra vinculada a las características del funcionario, es decir, a sus concretas condiciones subjetivas, sino al puesto de trabajo que este desarrolla. En este sentido, hay que tener en cuenta cómo, en la regulación prevista en la LMRFP ${ }^{23}$ y, en la actualidad, en el EBEP en los términos indicados, se pone de manifiesto la opción del legislador de vincular la retribución, en concreto, por lo que

22 Vid. SSTSJ de Cantabria (Sala de los Contencioso-administrativo) de 25 de junio de 2008 (rec. 794/2007). En los mismos términos, con respecto a la regulación prevista al respecto en el art. 15 del RD 662/2001, SSTSJ de Cantabria (Sala de los Contencioso-administrativo) de 21 de diciembre de 2005 (rec. $787 / 2004$ ) y de 24 de octubre de 2005 (rec. 786/2004).

23 Vid. al respecto, CASTILLO BLANCO, F.A. (2002: 200-217). 
aquí interesa, el complemento específico, al puesto de trabajo, en la medida en la que existan determinadas circunstancias objetivas ${ }^{24}$, y no a la carrera ${ }^{25}$.

Pues bien, este complemento también se contempla en la regulación que se aplica a los miembros de las Fuerzas Armadas ${ }^{26}$. En este supuesto, el legislador para proceder a la adaptación parte de lo establecido en el art. 23.3 b) de la LMRFP, pero, como se analizará, no lo vincula única y exclusivamente al puesto de trabajo, como se ha señalado, sino que también tiene en cuenta el empleo del sujeto; lo que ha quedado reflejado en la normativa sobre retribuciones de las Fuerzas Armadas ${ }^{27}$, y, en concreto, en la actualidad, en el art. 3.3 del RD 1314/2005 en el que se puede comprobar cómo en este caso, aunque el legislador mantiene la denominación prevista para los funcionarios civiles, en realidad esto no implica que se equipare, ya que, como se ha indicado, no existe una identidad entre el sistema retributivo militar y el civil, lo que se pone de manifiesto con respecto a este complemento, y no solo por el hecho, como se puede observar, de que para el personal de las Fuerzas Armadas en el mismo se integren, de un lado, un componente general y, de otro, un componente singular, sino fundamentalmente por "la diferente caracterización jurídica del llamado "complemento específico" en uno y otro sector de la función pública"28.

\section{El componente general del complemento específico y su percepción en función del empleo}

A pesar de que en el caso de la función pública civil el complemento específico está vinculado al puesto de trabajo y, en concreto, a las circunstancias que concurren en el mismo, el legislador a la hora de adaptar la regulación prevista al efecto para

24 Vid. GASTILlO BLANCO, F.A., "Los derechos retributivos de los empleados públicos", en SÁNCHEZ MORÓN, M. (dir.), Comentarios a la Ley del Estatuto Básico del Empleado Público, Lex Nova, Valladolid, 2008, p. 258.

25 Vid. PALOMAR OLMEDA, A., Derecho de la Función Pública. Régimen jurídico de los funcionarios públicos, Dykinson, S.L., Madrid, 2016, p. 399: este complemento "es el instrumento técnico imprescindible para la implantación de un régimen basado en todo o en parte en la valoración de puesto de trabajo, opuesto al de carrera o de cuerpos". Un complemento que debe incluirse en las relaciones de puestos de trabajo de las Administraciones Públicas, tal y como ya se establecía en el art. 15 de la LMRFP y como, en la actualidad, se contempla en el art. 74 del EBEP.

26 Y, al igual que se indica en el EBEP, en el art. 17.2 de la Ley 39/2007, de 19 de noviembre, de la carrera militar (LCM), BOE de 20 de noviembre de 2007, se establece que en las relaciones de puestos militares se especificarán, entre otros aspectos, sus retribuciones complementarias entre las que, como se ha indicado, también se encuentra el citado complemento específico.

27 Vid. art. 4.3 Real Decreto 359/1989, de 7 de abril, BOE de 13 de abril de 1989; art. 4.3 del Real Decreto 1494/1991, de 11 de octubre, BOE de 15 de octubre de 1991; art. 5 apartados $2.2^{\circ}$ y $3.1^{\circ}$ del RD $662 / 2001$.

28 SSTS (Sala de lo Contencioso-administrativo) de 20 de junio de 2005 (rec. 46/2003) y de 25 de febrero de 2002 (rec. 1619/2000). 
este colectivo ha tenido en cuenta las citadas singularidades que concurren en las Fuerzas Armadas, en particular, su estructura jerarquizada y las peculiaridades de la carrera militar, de modo que ha establecido el denominado componente general del complemento específico. En concreto, el art. 3.3 del RD 1314/2005 señala que "el componente general es la parte del complemento específico que se percibe en función del empleo que se tenga, siguiendo un orden jerárquico dentro de cada categoría" 29 . De este modo, como se puede constatar, el citado componente no se vincula al puesto de trabajo, sino al empleo del sujeto, se percibe con independencia del destino que ocupe y, de forma indirecta, conecta con la responsabilidad que este tiene por haber alcanzado un empleo. Así, aunque tanto en la función pública civil como en la militar se haga referencia al complemento específico, este componente determina que no compartan la misma naturaleza jurídica, sobre todo si se tiene en cuenta que lo relevante en el ámbito civil es el puesto de trabajo ${ }^{30}$.

Como se puede comprobar, la regulación actual no es la misma que se venía aplicando. En la regulación prevista en el RD 662/2001, el componente general venía escalonado por empleos dentro de cada categoría (oficiales, suboficiales, y tropa o marinería), y entre categorías, si bien la lógica de su variación según el empleo alcanzado y su progresión en el mismo no se reflejaba en todos los supuestos al aplicar la regulación prevista en el art. 5.2.2 ${ }^{\circ}$ del RD 662/2001, ya que, en algunos casos, las cuantías que percibían los sujetos con los empleos más altos de la categoría inferior eran superiores a las asignadas a los primeros empleos de la categoría superior $^{31}$. Esto determinaba que no existiese una clara progresión entre el avance en la carrera militar y el incremento en la cuantía del citado componente, por lo que no se podía afirmar que se percibiese con absoluta regularidad; de hecho, como señalaba la norma, en la atribución de este complemento no existía "una relación directa con el orden jerárquico". Sin embargo, tras la entrada en vigor del RD 1314/2005 se puede apreciar cómo cambia esa situación ya que, aunque sigue vinculado al empleo alcanzado por el sujeto, se establecen nuevas cuantías y una relación con el orden jerárquico, de forma que la retribución obedece en mayor medida a la progresión de la carrera profesional.

29 Una norma que vino a modificar la regulación prevista al respecto en el art. 5.2 $2^{\circ}$ del RD 662/2001, en el que se contemplaba este componente también "como parte del empleo ostentado", aunque en esta norma se establecía que esto no suponía "una relación directa con el orden jerárquico", y también se indicaba que no lo percibiría "el soldado profesional de tropa y marinería con menos de dos años de servicios".

30 SSTS (Sala de lo Contencioso-administrativo) de 20 de junio de 2005 (rec. 46/2003) y de 25 de febrero de 2002 (rec. 1619/2000).

31 Vid. SALVADOR CENTELLES, V. (2005: 336). 
Es cierto que, tal y como se ha analizado, determinados puestos de trabajo pueden ser desempeñados indistintamente por personal con diferentes empleos (por ejemplo, subteniente, brigada, sargento primero o sargento), ahora bien, al igual que se ha observado para el complemento de empleo, en este caso no cabe exigir un componente general vinculado a un empleo superior de los que puedan ostentarse para ocupar una vacante, sino al efectivamente ostentado ${ }^{32}$. Por tanto, en este sentido, no es posible equiparar la regulación de este complemento en la función pública civil y en la militar, y, en concreto, en este supuesto en el que precisamente se pone de manifiesto la adaptación de la primera a las peculiaridades de la carrera militar y a la estructura jerarquizada de las Fuerzas Armadas. Lo que tampoco cabe es vincular en este caso, de forma excepcional, el componente general del complemento específico al puesto de trabajo ocupado y no al concreto empleo, de modo que se parta de la similitud de funciones que se llevan a cabo por sujetos que tienen diferentes empleos y se exija por esta vía la percepción del componente general previsto para un empleo superior, como puede ser el caso de un cabo primero que realiza funciones similares a las de un sargento ${ }^{33}$.

De todos modos, también hay que tener en cuenta, como se ha señalado, que los miembros de las Fuerzas Armadas pueden ocupar puestos de trabajo incluidos en las relaciones de puestos de trabajo del Ministerio de Defensa y sus organismos autónomos, de forma que, de acuerdo con lo establecido en el art. 11 del RD 1314/2005, recibirán las retribuciones complementarias asignadas al puesto que desempeñen. Así, en este supuesto, aunque el componente general del complemento específico esté vinculado al empleo del sujeto, lo relevante a estos efectos será el puesto de trabajo ocupado $^{34}$.

\section{El componente singular del complemento específico}

Como se ha indicado, otro de los componentes del complemento específico es el componente singular y tiene como finalidad retribuir las especiales condiciones del puesto de trabajo. Un componente que, tal y como se establece en el preámbulo del RD 1314/2005, se venía vinculando al empleo, si bien, tras la entrada en vigor

32 Vid. STSJ de Andalucía, Granada (Sala de lo Contencioso-administrativo) de 20 de febrero de 2012 (rec. 1659/2007); SSTSJ de Madrid (Sala de lo Contencioso-administrativo) de 17 de julio de 2008 (rec. 615/2005, 221/2005, 622/2005, 685/2005) de 28 de julio de 2008 (rec. 686/2005) y STSJ de la Comunidad Valenciana (Sala de lo Contencioso-administrativo) de 26 de junio de 2009 (rec. 1559/2007).

33 Vid. STSJ de Madrid (Sala de lo Contencioso-administrativo) de 30 de diciembre de 2009 (rec. 268/2008).

34 Vid. SSTSJ de Cantabria (Sala de los Contencioso-administrativo) de 25 de junio de 2008 (rec. 794/2007). En los mismos términos, con respecto a la regulación prevista al respecto en el art. 15 del RD 662/2001, SSTSJ de Cantabria (Sala de los Contencioso-administrativo) de 21 de diciembre de 2005 (rec. $787 / 2004$ ) y de 24 de octubre de 2005 (rec. 786/2004). 
de esta norma, pasó a convertirse en un elemento retributivo destinado a compensar "las características y circunstancias específicas del puesto desempeñado".

\section{A. Vinculación al puesto de trabajo}

El art. 3.3 del RD 1314/2005 indica que el componente singular del complemento específico retribuye "las particulares condiciones de responsabilidad, preparación técnica, peligrosidad y penosidad del puesto”. De este modo, la norma recoge algunos de los factores establecidos en el art. 23.3.b) de la LMRFP y en el art. 24.b) del EBEP, a los que ya se ha hecho referencia, y, en particular, la peligrosidad y la penosidad del puesto; factores que igualmente se pueden incluir en la referencia genérica prevista en este último artículo, esto es, "las condiciones en que se desarrolla el trabajo". En este sentido, teniendo en cuenta lo anterior, es importante recordar que el TS ha señalado las características fundamentales del complemento específico partiendo de lo establecido en el art. 23 b) de la LMRFP. En particular, de un lado, "la concreción", ya que "se fija atendiendo precisamente a las características de "un" puesto de trabajo", y, de otro, "la objetividad", puesto que "se atiende a las condiciones particulares de ese puesto de trabajo y no a los cuerpos o escalas de los funcionarios que las desempeñan"; así, "es el contenido del puesto de trabajo el que determina el complemento específico" "35. En este supuesto, se puede afirmar que este componente tiene una clara naturaleza objetiva, ya que son las características del puesto las que van a determinar su asignación y su cuantía; lo que supone que queda al margen a estos efectos la concurrencia de determinados aspectos de carácter subjetivo vinculados a la persona que desempeña el puesto de trabajo, como puede ser el hecho de que el funcionario que lo ocupa tenga una mayor o menor preparación. Por tanto, lo relevante en este caso son las peculiaridades y las características del puesto de trabajo ${ }^{36}$. En definitiva, la percepción del componente singular de este comple-

35 Vid. SSTS (Sala de lo Contencioso-administrativo) de 1 de julio de 1994 (rec. 9074/1992), de 4 de julio de 1994 (rec. 7922/1992), y de 22 de diciembre de 1994 (rec. 600/1993).

36 Vid. SSTSJ de Andalucía, Sevilla (Sala de lo Contencioso-administrativo) de 2 de junio de 2011 (rec. 522/2010): "a pesar de que los puestos señalados que ha venido ocupando no precisaban del Título/ Diploma referenciado, al punto que no ha realizado el correspondiente curso de especialización, desde su presentación en la Unidad el 5 de Octubre de 2004 por parte del Mando de la misma se le ordena pasar a prestar servicios de Suboficial Operador de los referidos sistemas, turnándose para ello con los distintos Oficiales que ocupaban puestos con exigencia del mencionado título y desarrollando las mismas funciones y tareas que éstos, pese a lo cual percibía una cuantía inferior en concepto de componente singular del complemento específico lo que supone un agravio comparativo sin justificación objetiva y razonable dada la naturaleza objetiva del referido complemento que retribuye las especiales características que concurren en cada puesto en cuestión"; y de 10 de febrero de 2012 (rec. 520/2010): "Es, pues, un concepto retributivo que tiene una clara naturaleza objetiva, en tanto que son las características del puesto de trabajo las que determinan su procedencia y cuantía. Ello significa, por una parte, que es totalmente ajeno a todo matiz subjetivo derivado de la persona titular del puesto que lo desempeña, por tanto, resulta indiferente a los efectos que en este interesa el grado de preparación en concreto que posea el funcionario que en un mo- 
mento no se encuentra vinculada a las características del funcionario, es decir, a sus concretas condiciones subjetivas, sino al puesto de trabajo que este desarrolla ${ }^{37}$, como sucede en el ámbito civil con respecto al complemento específico.

Ahora bien, si solo se hace referencia a los mencionados factores, por lo que aquí interesa, en principio, no parece que existan muchas diferencias entre la regulación anterior contenida en el art. 5.3.1 ${ }^{\circ}$ del RD 662/2001, en la que se establecía que "retribuye las especiales condiciones en que la unidad de destino desarrolle su actividad, así como dentro de la misma, las particulares o singulares condiciones de determinados destinos, la especial responsabilidad, preparación técnica, peligrosidad o penosidad", y la regulación vigente, sin embargo la realidad es otra. Es cierto que el art. 5.3 del RD 662/2001 ya venía señalando esos factores, y, por tanto, desde ese punto de vista, el componente también se venía vinculando al puesto, de hecho, el TS ya destacaba en este sentido la existencia de "una sustancial identidad" entre esa parte del complemento, a la que hacía referencia en términos de "complemento específico "singular" militar" y el específico en el ámbito de la función pública civil regulado en el art. 23 de la LMRFP, al señalar que "ambos se definen por los mismos parámetros"38; si bien, en la práctica este componente se vinculaba, de forma indirecta, al empleo, puesto que se establecían cuatro tipos por cada empleo y su cuantía variaba, precisamente, según el empleo ${ }^{39}$. Así, la regulación prevista en el RD 1314/2005 supone un cambio ya que, en la actualidad, el componente singular se vincula al puesto. Es decir, los puestos pueden tener asignado un componente singular de los previstos en el anexo IV del RD 1314/2005, cuyas cuantías pueden ser modificadas por la Comisión Superior de Retribuciones Militares, previo informe favorable del Ministerio de Economía y Hacienda, que compensa las características

mento determinado ocupe el puesto de trabajo, o los cursos que se le pudieran exigir para ocuparlo. En definitiva, se trata de un complemento que se refiere a peculiares y concretas características del puesto de trabajo, no a la mayor o menor preparación del funcionario que lo ocupa". Vid. OBSERVATORIO DE LA VIDA MILITAR, Memoria Informe año 2016, 2017, en http:/ /www.observatoriodelavidamilitar.es/informes. html, pp. 171 y 172, en concreto, Anexo I (Componente singular del complemento específico: criterios generales de valoración del puesto y asignación de niveles).

37 STSJ de Andalucía (Sala de lo Contencioso-administrativo) de 2 de junio de 2011 (rec. 522/2010): "para su asignación ha de haber una decisión administrativa en el sentido de asignar el mismo al puesto de trabajo. Asignación del componente singular del complemento específico, de carácter objetivo y ajeno de todo punto a criterios subjetivos de los que ocupen un determinado puesto de trabajo. Por tanto, el proceso de asignación, por su propia naturaleza, además de singular prescinde de los titulares de cada uno de los puestos de trabajo, estos no forman ni conforman el proceso de asignación, que por ser una decisión discrecional de la Administración resulta ajeno a los titulares de cada puesto de trabajo".

38 SSTS (Sala de lo Contencioso-administrativo) de 20 de junio de 2005 (rec. 46/2003) y de 25 de febrero de 2002 (rec. 1619/2000).

39 Un componente, además, cuya cuantía venía siendo muy escasa y, en algunos casos, inexistente, lo que se ha podido comprobar en los empleos más inferiores de cada categoría Vid. SALVADOR CENTELLES, V. (2005: 337). 
y circunstancias singulares del puesto y figura en la relación de puestos militares, siendo su percepción independiente del empleo del militar que ocupe el puesto. Por tanto, aunque la finalidad de este componente sigue siendo la misma, no lo es su estructura, ni tampoco las cuantías. En concreto, en el citado anexo se establece un listado de 35 posibles valores de este componente, desvinculándose del empleo o de los empleos que se exijan en la plantilla de destinos para su ocupación, de forma que el puesto puede tener establecido uno de esos valores. De este modo, en todo caso, la percepción de este componente dependerá del puesto de trabajo desempeñado ${ }^{40}$.

\section{B. ¿Hasta qué punto tiene relevancia el empleo en la práctica?}

Hay que tener en cuenta que ciertos factores, como sucede con la responsabilidad o con la preparación técnica, estarán vinculados a determinados empleos, por lo que no es posible afirmar que no existe una relación entre el empleo y este tipo de componente, ya que, habitualmente, una mayor responsabilidad está asociada a los empleos superiores ${ }^{41}$. Desde este punto de vista, se puede comprobar cómo en la práctica se proyecta de nuevo el empleo a la hora de concretar la cuantía del complemento. De hecho, ya en el año 2005 se podía apreciar cómo se establecía una progresión en el incremento de la cuantía dependiendo de los niveles y cómo ascendía de manera considerable en los niveles superiores. Es cierto que esos niveles se asignan por puestos, por lo que el hecho de que no exista una progresión uniforme en los niveles inferiores y superiores no debería plantear un problema, sin embargo se genera cuando se puede observar que se parte de una valoración previa en la que el factor relativo a la responsabilidad predomina de forma especial a la hora de efectuarla, sobre todo por el hecho de que, como se ha señalado, la responsabilidad se vincula al empleo y este ya se retribuye con el complemento de empleo, así como con el componente general a los que se ha hecho referencia.

Como contrapartida, también se ha cuestionado hasta qué punto debe percibir el funcionario este componente cuando realiza las mismas funciones teniendo en cuenta el tramo de empleos, es decir, cuando las funciones son iguales pero los empleos varían. Si bien, dada la naturaleza del componente singular y ya que lo im-

40 Vid. STSJ Cantabria (Sala de lo Contencioso-administrativo) de 25 de junio de 2008 (rec. $794 / 2007)$.

41 Vid. STSJ de Andalucía, Sevilla (Sala de lo Contencioso-administrativo) de 18 mayo 2012 (rec. 466/2011): "las condiciones de los puestos a que se asignan el componente singular del complemento específico de nivel 12 (de subteniente a sargento primero) o de nivel 14 (de subteniente a brigada) difieren tanto en lo relativo al grado de responsabilidad profesional (superior cuanto mayor sea el empleo), como a la entidad, especialización y carácter de las funciones desempeñadas (pues las que tienen asignada el componente singular del complemento específico de nivel 14 son las adecuadas a puestos de Jefatura de la Oficina Técnica, de Jefatura de Equipo de Control de Producción, o de Control de Calidad, entre otros; distintas a las que corresponden al puesto de trabajo ocupado por el actor)". 
portante son los trabajos realizados, aunque no exista una coincidencia en cuanto a los empleos, si los trabajos son iguales el funcionario debe percibirlo ${ }^{42}$. No obstante, lo recibirá mientras desempeñe el puesto ${ }^{43}$, de forma que la asignación de un nuevo puesto no puede ser interpretada a efectos retributivos como una modificación de las características retributivas del puesto que venía ocupando, sino que en ese caso dejará de percibir el componente singular del complemento específico vinculado al mismo y se le asignará, en su caso, el correspondiente al nuevo puesto de trabajo, sin que quepa exigir, en el supuesto en el que este último sea inferior, que se le abonen las diferencias con respecto al que hasta ese momento venía percibiendo ${ }^{44}$.

\section{El efectivo desempeño del puesto}

El hecho de que el componente singular del complemento específico retribuya "las particulares condiciones de responsabilidad, preparación técnica, peligrosidad y penosidad del puesto" (art. 3.3 del RD 1314/2005) conlleva que "su percibo se halla vinculado al efectivo desempeño del puesto de trabajo de que se trate, de tal suerte que, producido el cese, deja de cobrarse ${ }{ }^{45}$, lo que, a su vez, supone que no se tendrá derecho a percibirlo cuando no se desempeñe un puesto cuyas características sean consideradas para asignarlo. Ahora bien, con respecto a lo señalado, se ha cuestionado si debe percibirse este componente singular en función del puesto efectivamente desempeñado cuando este se ocupe con carácter interino. En este sentido, cabe destacar cómo los Tribunales Superiores de Justicia han dictado sentencias favorables al abono del mismo, al margen de que el puesto se desempeñe de forma interina ${ }^{46}$; su-

42 Cfr. SSTSJ de la Rioja (Sala de lo Contencioso-administrativo) de 17 de mayo de 2012 (rec. 334/2011): "las funciones de cada una de las personas no varía, siendo en este caso, las propias de un especialista en Mantenimiento de Aeronaves (MAERN), independientemente de en que tramo de empleos se anuncie y cubra la vacante que se ocupe y, por tanto, las funciones a desarrollar en los diversos puestos de subteniente a sargento primero del Cuerpo de Especialistas, de la especialidad fundamental MAERN, son coincidentes con las de los puestos de subteniente a brigada del mismo cuerpo y especialidad fundamental" y de 27 de junio de 2012 (rec. 325/2011).

43 Vid. OBSERVATORIO DE LA VIDA MILITAR (2017: 95): "goza de estabilidad temporal en tanto en cuanto no se cambie de destino".

44 Vid. SAN (Sala de lo Contencioso-administrativo) de 29 de enero de 2014 (rec. 455/2011): "La consideración como nuevo destino del asignado al recurrente, rechazándose que se haya producido la modificación de una de las cualidades del anteriormente ocupado, hace caer por su base todas las argumentaciones de la demanda, que tienen como presupuesto una modificación en las características retributivas del puesto de trabajo que se ocupaba, cuando, se insiste, lo que se ha producido es la asignación de uno nuevo, que posee otras, entre las que figura un componente singular del complemento específico inferior".

45 Cfr. STSJ Castilla y León, Burgos (Sala de lo Contencioso-administrativo) de 13 de mayo de 2016 (rec. 106/2015).

46 Entre otras, cabe destacar STSJ País Vasco (Sala de lo Contencioso-administrativo) de 28 de mayo de 2013 (rec. 883/201 1); SSTSJ Madrid (Sala de lo Contencioso-administrativo) de 7 de abril de 2016 (rec. 94/2015); de 13 de septiembre de 2018 (rec. 260/2017); de 9 de octubre de 2018 (rec. 188/2017); de 8 
puesto en el que se ha venido negando por parte de la Administración su percepción, para lo que se ha recurrido a lo establecido en el apartado sexto, párrafo segundo, de la Orden Ministerial 189/2001, de 10 de septiembre, por la que se dictan normas para la aplicación del componente singular del complemento específico ${ }^{47}$, en el que se indica que "no se modificará la percepción de este complemento aunque se esté desempeñando de manera accidental, interina, en funciones, por ausencia o por cualquier otra circunstancia, otro destino que tenga distinto tipo de componente singular del complemento específico". Sin embargo, no hay que olvidar que, a diferencia de la regulación prevista para este componente en el RD 662/2001, en la contenida en el RD 1314/2005 este componente no se vincula directamente al empleo, sino, como se viene señalando, a las características y circunstancias concretas del puesto que desempeña el sujeto. Por tanto, si el citado componente retribuye las condiciones particulares del puesto de trabajo y se devenga por el efectivo desempeño del puesto ${ }^{48}$, el funcionario debería percibirlo, de otro modo la situación resultaría contraria al principio de igualdad; a igual trabajo no recibiría la misma retribución tal y como contempla la norma ${ }^{49}$.

Con respecto a lo señalado en la citada Orden se ha indicado que esta no tiene una verdadera naturaleza normativa, ya que se dictó por el Ministro de Defensa para determinar los criterios de asignación de este componente y con el objetivo de que el Consejo de Ministros aprobara la relación inicial de destinos con derecho al complemento $^{50}$. Y, además, se ha considerado que, aunque la tuviera, si se tiene en cuenta lo establecido en el último párrafo del apartado sexto de dicha Orden, en el que se indica que "cuando un militar desempeñe en comisión de servicio un destino que se encuentre vacante, sin pérdida del destino anterior, percibirá las retribuciones

de noviembre de 2018 (rec. 283/2018); de 26 de diciembre de 2018 (rec. 160/2017); de 4 de marzo de 2019 (rec. 187/2018); de 19 de marzo de 2019 (rec. 529/2017) y de 29 de marzo de 2019 (rec. 201/2018).

47 Boletín Oficial de Defensa (en adelante, BOD) de 12 de septiembre de 2001.

48 Sin que sea necesario que el sujeto pruebe que ha realizado efectivamente la totalidad de las funciones, vid. SSTSJ Madrid (Sala de lo Contencioso-administrativo) de 7 de abril de 2016 (rec. 94/2015), de 8 de noviembre de 2018 (rec. 283/2018), de 4 de marzo de 2019 (rec. 187/2018) y de 19 de marzo de 2019 (rec. 529/2017): "en el concreto caso del personal militar tal exigencia vendría referida a la de un hecho negativo pues las Reales Ordenanzas (art. 55.2) establecen que la responsabilidad en el mando "no es renunciable ni puede ser compartida", de modo que el pleno ejercicio del mando de la Unidad o Dependencia es un hecho amparado por una presunción legal que no precisaría de acreditación por el interesado sino, al contrario, el incumplimiento de tal obligación, por parte de la Administración”. Por tanto, se invierte de este modo la carga de la prueba.

49 Cfr. SSTSJ Madrid (Sala de lo Contencioso-administrativo) de 9 de octubre de 2018 (rec.188/2017), de 8 de noviembre de 2018 (rec. 283/2018), de 9 de octubre de 2018 (rec. 169/2017) y STSJ Cataluña (Sala de lo Contencioso-administrativo) de 21 de diciembre de 2012 (rec. 2343/2008).

50 Cfr., entre otras, SSTSJ Madrid (Sala de lo Contencioso-administrativo), de 9 de octubre de 2018 (rec. 188/2017); de 9 de octubre de 2018 (rec. 169/2017), de 8 de noviembre de 2018 (rec. 283/2018); de 26 de diciembre de 2018 (rec. 160/2017) y de 29 de marzo de 2019 (rec. 201/2018). 
que correspondan al destino mejor retribuido y en las cuantías correspondientes al empleo que ostenta", en este caso podría aplicarse al tratarse de un supuesto análogo, lo que se justifica por la naturaleza del componente singular específico que queda vinculado al puesto que se desempeña ${ }^{51}$. De otro modo, "se produciría un enriquecimiento injusto para la Administración" 52 en perjuicio del funcionario ${ }^{53}$.

Pues bien, con el fin de armonizar lo dispuesto en la normativa a la que se ha hecho referencia con los pronunciamientos de los Tribunales Superiores de Justicia, por Resolución 434/193/2019, del subsecretario de Defensa, de 11 de octubre, se han establecido criterios para la asignación del componente singular del complemento específico que corresponde por el desempeño del puesto de forma interina, tal y como se establece en la misma. De este modo, el personal militar "percibirá el componente singular del complemento específico establecido para ese puesto que ocupe con carácter interino, siempre que sea superior al que estuviera percibiendo" (segundo). Sin embargo, hay que tener en cuenta que en el caso de desempeño de funciones de forma accidental, de modo temporal, cuando el puesto a cubrir esté ocupado y sea preciso asumir las funciones por motivos de su cesión de mando, no se percibirá el citado componente singular del complemento específico asignado a dicho puesto (tercero).

51 Vid. al respecto, STSJ País Vasco (Sala de lo Contencioso-administrativo) de 28 de mayo de 2013 (rec. 883/2011); SSTSJ Madrid (Sala de lo Contencioso-administrativo) de 7 de abril de 2016 (rec. 94/2015); de 13 de septiembre de 2018 (rec. 260/2017); de 9 de octubre de 2018 (rec. 169/2017); de 9 de octubre de 2018 (rec. 188/2017); de 8 de noviembre de 2018 (rec. 283/2018); y de 29 de marzo de 2019 (rec. 201/2018).

52 Cfr. STSJ Cataluña (Sala de lo Contencioso-administrativo) de 21 de diciembre de 2012 (rec. 2343/2008): "en la medida en que el coste por el desempeño del puesto ha sido inferior al que se hubiera tenido que asumir en el caso de que se hubiera cubierto el puesto vacante, lo que da lugar a una situación abusiva, desconocedora de los derechos estatutarios de los funcionarios, que el Derecho no puede amparar, pues no solo se vulnerarían derechos sociales fundamentales de los trabajadores en la medida en que a igual trabajo no se percibiría igual salario, sino que se crearía un marco fáctico reiterado y pernicioso que permitiría los abusos derivados de la utilización de este tipo de mecanismos de sustitución en caso de vacantes o cuando, por las razones que sean, su titular no desempeñe el puesto".

53 Vid. SSTSJ Madrid (Sala de lo Contencioso-administrativo) de 9 de octubre de 2018 (rec. 188/2017); de 9 de octubre de 2018 (rec. 169/2017); de 8 de noviembre de 2018 (rec. 283/2018); de 26 de diciembre de 2018 (rec. 160/2017) y de 29 de marzo (rec. 201/2018): "lo que no es posible es que la Administración que no provee un puesto vacante con arreglo a derecho (lo que comportaría el abono del correspondiente complemento específico) obtenga un beneficio de ello en perjuicio del funcionario que lo desempeña de hecho". Ahora bien, lo que no cabe es pretender percibir el mismo componente singular cuando las condiciones particulares de desempeño de los puestos son diferentes teniendo en cuenta los factores a los que hace referencia la norma. 
D. La valoración de los factores que determinan la asignación del componente singular

Es importante recordar, por lo que aquí interesa, que, de acuerdo con lo previsto en el art. 17.2 de la LCM, en las relaciones de puestos militares se especificarán la descripción de cada puesto, su asignación por cuerpos y escalas, empleos y especialidades, sus retribuciones complementarias y las condiciones y requisitos para su ocupación; lo que se corresponde con lo establecido en el art. 74 del EBEP en el que se indica que las Administraciones Públicas estructurarán su organización a través de relaciones de puestos de trabajo u otros instrumentos organizativos similares que comprenderán, al menos, la denominación de los puestos, los grupos de clasificación profesional, los cuerpos o escalas, en su caso, a que estén adscritos, los sistemas de provisión y las retribuciones complementarias. En este sentido, hay que tener en cuenta que el TS ha señalado que las relaciones de puestos de trabajo tienen naturaleza de actos administrativos y no de reglamentos ${ }^{54}$. Desde este punto de vista, la relación de puestos de trabajo "no es un acto ordenador, sino un acto ordenado mediante el que la Administración se autoorganiza, ordenando un elemento de su estructura como es el del personal integrado en ella" ${ }^{55}$, por lo que no es la relación de puestos la que regula los deberes y derechos de los funcionarios, estos vienen regulados en las normas, "siendo la configuración del puesto de trabajo definido en la relación de puestos de trabajo simplemente la singularización del supuesto de hecho de aplicación de dichas normas" ${ }^{\prime 6}$.

De este modo, la valoración de los factores que determinan la asignación del componente singular del complemento específico entra dentro de la potestad discrecional de autoorganización de la Administración. Ahora bien, tal y como ha señalado el TS con respecto a este complemento en el ámbito civil, "esto no quiere decir que la Administración goce de un apoderamiento totalmente discrecional, desligado de los conceptos legales que justifican las distinciones que pueda introducir" 57; "discrecional no es sinónimo de arbitrariedad" 58 . Esa potestad debe ser ejercida en el marco de lo establecido en la norma, es decir, la Administración debe valorar la asignación del componente singular del complemento específico, teniendo en cuenta los criterios

\footnotetext{
54 Cfr. STS (Sala de lo Contencioso-administrativo) de 5 de febrero de 2014 (rec. 2986/2012).

55 Cfr. STS (Sala de lo Contencioso-administrativo) de 5 de febrero de 2014 (rec. 2986/2012) y STSJ de la Rioja (Sala de lo Contencioso-administrativo) de 24 de enero de 2018 (rec. 293/2017).

56 Vid. STSJ de Castilla y León, Valladolid (Sala de lo Contencioso-administrativo) de 15 de mayo de 2015 (rec. 475/2012).

57 Vid. STS (Sala de lo Contencioso-administrativo) de 27 de septiembre de 1994 (rec. 81/1990).

58 Vid. STSJ de Castilla y León, Burgos (Sala de lo Contencioso-administrativo) de 30 de noviembre de 2018 (rec. 152/2017); SSTSJ de Madrid (Sala de lo Contencioso-administrativo) de 23 de marzo de 2017 (rec. 683/2015) y de 7 de abril de 2016 (rec. 94/2015).
} 
previstos en la misma y las circunstancias de cada puesto ${ }^{59}$. De esa forma, se delimita esa potestad y se establecen elementos que van a fundamentar y determinar la asignación de las retribuciones en este caso del componente singular. En este sentido hay que recordar que, tal y como ha señalado el Tribunal Constitucional (TG), la Administración Pública "en sus relaciones jurídicas no se rige, precisamente, por el principio de la autonomía de la voluntad, sino que debe actuar con sometimiento pleno a la Ley y al Derecho (art. 103.1 CE), con una interdicción expresa de arbitrariedad (art. 9.3 CE)" y, "como sujeto público que es, está sujeta al principio de igualdad ante la Ley que, como hemos declarado, constitucionalmente concede a las personas el derecho subjetivo de alcanzar de los poderes públicos un trato idéntico para supuestos iguales" ${ }^{\prime 60}$; lo que comprende un trato retributivo idéntico respecto al aplicado a los funcionarios que estén en condiciones iguales a las del afectado. Así, a iguales condiciones debe corresponder el mismo componente ${ }^{61}$, por lo que, en estos casos, "ante supuestos de hecho idénticos, cualquier diferencia de trato retributivo deberá estar objetivamente justificada, ya que de lo contrario será discriminatorio y, en consecuencia, lesivo del derecho consagrado en el art. $14 \mathrm{CE}^{\prime 62}$. En este caso, como se ha señalado, este componente tiene una naturaleza objetiva, puesto que son las características del puesto las que van a determinar su asignación y su cuantía. Esto conlleva que una atribución discrecional del mismo debe centrarse única y exclusivamente en esta naturaleza, de modo que no cabe introducir una diferencia de trato retributivo teniendo en cuenta la concurrencia de ciertos aspectos de carácter subjetivo vinculados a la persona que desempeña el puesto de trabajo; si así fuese sería discriminatoria ${ }^{63}$.

\section{EL GOMPLEMENTO DE DEDICAGIÓN ESPEGIAL}

En el ámbito militar se puede observar cómo en el art. 3.4 del RD 1314/2005, al igual que en normas anteriores, como en los derogados art. 4.4 del Real Decreto 359/1989, de 7 de abril, de retribuciones del personal de las Fuerzas Armadas ${ }^{64}$, art. 4.4 del Real Decreto 1494/1991, de 11 de octubre, por el que se aprueba el reglamen-

59 Vid. STSJ de Andalucía, Sevilla (Sala de los Contencioso-administrativo), de 2 de junio de 2011 (rec. 522/2010).

60 SSTC 161/1991, de 18 de julio, FJ 1; 2/1998, de 12 de enero, FJ 3; y 34/2004 de 8 marzo, FJ 3.

61 Vid. STSJ de Castilla y León, Burgos (Sala de lo Contencioso-administrativo), de 30 de noviembre de 2018 (rec. 152/2017); SSTSJ de Madrid de 23 de marzo de 2017 (rec. 683/2015) y de 7 de abril de 2016 (rec. 94/2015).

62 STC 161/1991, de 18 de julio, FJ 1.

63 Vid. STSJ de Andalucía, Sevilla (Sala de lo Contencioso-administrativo), de 10 de febrero de 2012 (rec. 520/2010).

64 BOE de 13 de abril de 1989. 
to general de retribuciones del personal de las Fuerzas Armadas ${ }^{65}$ y art. 3.3.2 ${ }^{\circ}$ del RD 662/2001, se hace referencia al complemento de dedicación especial, en lugar de denominarlo de productividad como en el ámbito civil, con el fin de adaptar la propia denominación a las funciones encomendadas a las Fuerzas Armadas ${ }^{66}$.

\section{El especial rendimiento, la actividad extraordinaria o la iniciativa y su determinación en el ámbito militar}

En concreto, este complemento retribuye "el especial rendimiento, la actividad extraordinaria o la iniciativa con que se desempeñe el puesto" (art. 3.4 del RD 1314/2005), siendo el Ministerio de Defensa el que aprueba los criterios de asignación, así como las cuantías por abonar. En este sentido, se puede comprobar cómo el legislador prácticamente reproduce lo previsto en el art. 23.3.c) de la $\operatorname{LMRFP}^{67}$, como ya lo hacía en el citado RD 662/2001; lo que, en la actualidad, se corresponde con la retribución complementaria que se contempla en el art. 24.c) del EBEP que obedece a factores como "el grado de interés, iniciativa o esfuerzo con el que el funcionario desempeña su trabajo y el rendimiento o resultados obtenidos".

Pues bien, aunque, en mayor o menor medida, hay una coincidencia en cuanto a los factores que se tienen en cuenta, lo cierto es que existen ciertas particularidades en el ámbito militar que han de considerarse y que van más allá de la denominación que se contempla para este complemento. No tanto en el caso de la realización de funciones de carácter administrativo, en las que no se aprecia realmente una diferencia con las que pueda llevar a cabo un funcionario civil, sino en la actividad específica de los ejércitos, vinculada a aspectos tales como la preparación del personal, o el uso de la fuerza, lo que, a su vez, se asocia a los fines que justifican su propia existencia y al hecho de que se exija a sus miembros una concreta disciplina y una disponibilidad permanente para el servicio, "incluso con la entrega de la vida cuando fuera necesario" (art. 6 de la LOFFAA); un aspecto que puede dificultar la propia determinación de la contraprestación económica en función de los factores que señala la norma. Sin olvidar que el legislador hace referencia a conceptos jurídicos indeterminados como

\section{BOE de 15 de octubre de 1999.}

66 Vid. al respecto, JANÉ ROCA, P., La evaluación de la productividad del empleado público: El caso de la Administración de la Generalitat de Cataluña (2009-2014), Universidad de Barcelona, Barcelona, 2017, en www. tesisenred.net/handle/10803/457563\#page $=1$, pp. 161 y ss.

67 Vid. PALOMAR OLMEDA, A., "Los límites jurisprudenciales sobre la fijación del complemento de productividad de los funcionarios: a propósito de las últimas sentencias sobre la materia", en Actualidad Jurídica Aranzadi, núm. 662 (2005), BIB 2005\686, p. 2: "se trata de una regulación especialmente parca de cara a construir una doctrina general fundada y completa sobre el mismo; CASTILLO BLANCO, F.A. "Luces y sobras del complemento de productividad ¿un concepto retributivo inaplicado?", en Fusticia Administrativa: Revista de Derecho Administrativo, núm. 8 (2000), pp. 5-24; y CASTILLO BLANCO, F.A. (2002: 219 y ss.). 
son "especial rendimiento", "actividad extraordinaria" o "iniciativa con que se desempeñe el puesto" ${ }^{\prime 68}$, como elementos que han de concurrir y ser objeto de valoración; lo que determinará que el sujeto tenga o no derecho a percibir el complemento.

En todo caso, hay que tener en cuenta, tal y como ha señalado el TS, por una parte, que este complemento "está dirigido a lograr una intensificación y calidad del trabajo", por lo que "su fijación dependerá de la productividad y de la mejora de resultados que individualmente se hayan obtenido en el desempeño de la función o trabajo, siendo esta la única causa motivadora de su devengo"; y, por otra, que tiene carácter "subjetivo o individualizado", no está vinculado al empleo, de modo que retribuye aspectos subjetivos "y no otro tipo de aspectos de carácter objetivo ligados al puesto de trabajo"69. Si bien, también hay que considerar que es la Orden Ministerial 190/2001, de 10 de septiembre, la que contiene normas para la aplicación del complemento de dedicación especial (en lo sucesivo, OM 190/2001) ${ }^{70}$. En particular, establece los criterios que se deben tener en cuenta a la hora de determinar quien debe percibir este complemento, como son el desarrollo de una jornada laboral superior a la establecida ${ }^{71}$; los trabajos que requieran una permanente localización; las actividades adicionales a desarrollar, o desarrolladas; el excepcional rendimiento; y la actividad extraordinaria e iniciativa en el desempeño del destino.

Como se puede constatar, estos criterios son bastante genéricos, sobre todo porque no se especifica, ni se indican las circunstancias que han de darse para aplicarlos al personal de las Fuerzas Armadas y que pueden determinar que perciba o no este complemento. No obstante, hay que tener en cuenta que en el apartado séptimo de la OM 190/2001 se autoriza al Subsecretario de Defensa a dictar las correspondientes normas de desarrollo de la misma. De este modo este dicta una Instrucción, por la que se autorizan los importes a abonar cada año en concepto de complemento de dedicación especial a los Ejércitos y otros organismos, y en la que también se recogen normas para su aplicación. Pues bien, uno de los problemas que se ha planteado al respecto ha sido el propio acceso a las Instrucciones, ya que se ha considerado que

68 Vid. STSJ de Andalucía, Sevilla (Sala de lo Contencioso-administrativo), de 18 de julio de 2008 (rec. 1114/2007).

69 Vid. SSTS (Sala de lo Contencioso-administrativo) 23 de mayo de 2008 (rec. cas. 672/2007), de 3 de julio de 2006 (rec. 2710/2001) y de 7 de marzo de 2005 (rec. 4246/1999).

70 BOD de 12 de septiembre de 2001.

71 En este sentido, se ha cuestionado si es posible considerar a estos efectos la prestación de servicios en turnos rotatorios, o en jornada festiva, o que se realice trabajo nocturno. Lo cierto es que la OM 190/2001 hace referencia a una jornada laboral superior a la establecida, pero el hecho de prestar servicios en esas circunstancias no implica necesariamente que sea así y que por ello exista una especial dedicación en términos de rendimiento, actividad extraordinaria e iniciativa. Vid. SSTSJ de Andalucía, Sevilla (Sala de lo Contencioso-administrativo) de 2 de junio de 2011 (rec. 522/2010) y de 10 de febrero de 2012 (rec. $520 / 2010)$. 
se trata de información que tiene carácter auxiliar o de apoyo, de acuerdo con lo establecido en el art. 18.1 b) de la Ley 19/2013, de 9 de diciembre, de transparencia, acceso a la información pública y buen gobierno ${ }^{72}$, en el que se indica que "se inadmitirán a trámite, mediante resolución motivada, las solicitudes" de acceso a la información pública que "referidas a información que tenga carácter auxiliar o de apoyo, como la contenida en notas, borradores, opiniones, resúmenes, comunicaciones e informes internos o entre órganos o entidades administrativas". Sin embargo, no cabe entender que las Instrucciones dictadas por el Subsecretario de Defensa se deban considerar como documentos auxiliares o de apoyo, por diferentes razones, entre las que cabe destacar que el acceso a su contenido es fundamental "para conocer cómo se distribuye y se percibe" este complemento, así como "la cuantía a distribuir en función del crédito aprobado para ello"; no se puede estimar que son documentos secundarios a estos efectos, ni que tienen "un carácter exclusivamente interno por el simple hecho de que sus efectos jurídicos- que claramente los produce- se circunscriben a un ámbito limitado, en este caso el de la Organización en la que son de aplicación"; además, teniendo en cuenta lo establecido en dichas Instrucciones, los sujetos a los que se les aplica podrán o no percibir esa retribución ${ }^{73}$. En resumen, para determinar si se percibe el complemento por el hecho de que concurran los criterios previstos en el RD 1314/2015, es decir, "el especial rendimiento, la actividad extraordinaria o la iniciativa con que se desempeñe el puesto", habrá que considerar los criterios que se establecen en la OM 190/2001 y su desarrollo en la correspondiente Instrucción.

En este sentido, se puede comprobar cómo, al margen de la dificultad para poder acceder a estas Instrucciones, el desarrollo varía de unas a otras, si bien, en todo caso, se puede constatar que se introducen determinados aspectos que van a condicionar la posibilidad de que el personal de las Fuerzas Armadas pueda percibir este complemento, como, por ejemplo, la realización de una determinada jornada, y/o un concreto horario ${ }^{74}$. Con respecto a lo señalado, hay que recordar que en la

72 BOE de 10 de diciembre de 2013.

73 En cuanto a las razones señaladas, cfr. Consejo de Transparencia y Buen Gobierno. Resolución 705/2018, de 19 de febrero de 2019. N/REF: R/0705/2018; 100-001936.

74 Tal y como se puede observar en la Instrucción 263/2001, de 14 de diciembre (Instrucción 263/2001), BOD de 18 de diciembre de 2001. En esta se establecieron dos modalidades de este complemento; modalidades que no se podían percibir de forma simultánea. De un lado, la de especial rendimiento, prevista para retribuir el "especial rendimiento, interés, e iniciativa" (punto tercero Instrucción 263/2001), aunque se limita el colectivo de sujetos que pueden percibirlo vinculándolo a la jornada y horario de especial dedicación, y estableciendo como condición la realización de una jornada de entre 8 y 12 horas semanales en horario de tarde, salvo, como en la citada Instrucción se indica, en el periodo en el que se implante la jornada de verano, sin perjuicio, por necesidades del servicio, del incremento horario que ocasionalmente sea preciso o de la fijación individualizada de la jornada vespertina, además de demostrar ese especial rendimiento, interés e iniciativa; y, de otro, la modalidad de actividad extraordinaria, vinculada a la eficacia en el desempeño de las labores (punto quinto Instrucción 263/2001), condicionando su percepción al hecho 
Orden DEF/1363/2016, de 28 de julio, por la que se regula la jornada y el régimen de horario habitual en el lugar de destino de los miembros de las Fuerzas Armadas (ODEF 2016) ( $^{75}$, se establecen distintos tipos de jornada, como la jornada general de trabajo, o la jornada especial, que en este caso conlleva la obligación de realizar una jornada de trabajo superior a la jornada general, sin olvidar la jornada de verano, a la vez que se contempla el horario de trabajo para las mismas y se indica, en algunos casos, la posibilidad de incrementarlo por necesidades del servicio (arts. 6 y 9). Aunque, es posible introducir adaptaciones al respecto por razones como el destino, o las necesidades específicas de determinadas unidades, bien a partir de determinadas remisiones o bien porque se permite que ciertos sujetos las establezcan (art. 5 de la ODEF 2016); lo que, a su vez, conlleva que se contemplen, según los casos, diferentes jornadas de trabajo u/y horarios. Además, tal y como se reconoce en la propia Exposición de Motivos de la ODEF 2016, también es posible que sea necesario que el personal militar preste servicios más allá de su horario habitual, lo que se deriva de la "disponibilidad permanente para el servicio que caracteriza" a este personal. De hecho, en el propio art. 10 de la ODEF 2016 se hace referencia a la modificación del horario habitual "por necesidades del servicio, adiestramiento, instrucción, guardias o servicios, o por el carácter operativo" de la unidades.

Pues bien, teniendo en cuenta lo anterior, lo cierto es que la percepción de este complemento puede quedar condicionada en algunos casos, no ya solo por la necesidad de que concurra un especial rendimiento, un interés o una iniciativa, ni por el hecho de estar localizable de forma permanente, sino que, además, se requiere que

de estar localizable de forma permanente y, además, a la realización de la misma jornada y horario que el titular del órgano del que dependa. En este sentido, como se puede comprobar, no basta con que el sujeto cumpla la condición de tener un especial rendimiento, interés o iniciativa, ni una mayor productividad, sino que, en realidad, en una y otra modalidad se vincula su percepción a una determinada jornada y a un cierto horario. Por su parte, en la Instrucción 23/2017, de 25 de mayo, del Subsecretario de Defensa, por la que se autorizan los importes a abonar en el año 2017 en concepto de complemento de dedicación especial a los Ejércitos y otros organismos, y se dictan normas para su aplicación (vid. OBSERVATORIO DE LA VIDA MILITAR (2017: 175-179), se puede comprobar cómo se trata de concretar cada uno de los criterios que se contemplan en la OM 190/2001, como la realización de una jornada laboral superior a la establecida, para lo que se tiene en cuenta el hecho de que se esté sujeto a horarios distintos y superiores a los que se contemplan en su unidad de destino; o de trabajos que requieran una permanente localización, si bien en este caso no se concreta, solo se indica que debe estar "permanentemente localizado durante la mayoría de los días del mes", sin especificar qué se entiende por esa mayoría que señala; o de actividades adicionales a desarrollar, o desarrolladas, considerando a estos efectos aquellos cometidos que se añadan a los correspondientes a su puesto de trabajo; o tener un excepcional rendimiento, vinculándolo a la realización de una jornada de especial dedicación, con el horario previsto al efecto; o, por último, la realización de una actividad extraordinaria e iniciativa en el desempeño del destino, para el personal que "en razón de su puesto de trabajo, realiza funciones de apoyo al Mando, debiendo estar sujeto a un horario que se encuentra supeditado a la jornada y horario de trabajo de la autoridad de la que se dependa, desempeñando sus cometidos con especial rendimiento, actividad extraordinaria e interés o iniciativa".

75 BOE de 10 de agosto de 2016. 
el sujeto realice una determinada jornada y/o un cierto horario. Lo relevante a estos efectos es que esto determina que queden excluidos de la posibilidad de percibir este complemento quienes no cumplan de forma conjunta estos requisitos; lo que supone que, finalmente, no solo se valora el hecho de que el sujeto tenga una especial dedicación en términos de rendimiento, actividad extraordinaria e iniciativa o que realice una jornada específica, sino que esa especial dedicación se produzca prestando servicios con una jornada y/o un horario determinados. En este sentido, se ha señalado que, de este modo, en realidad se desnaturaliza este complemento, ya que "sólo se está retribuyendo una jornada o un horario concreto, que se entiende que satisface las necesidades organizativas (...) que pueden resolverse asignando un complemento específico superior a los puestos que tienen determinados requisitos horarios"76. Ahora bien, es cierto que la jornada y el horario son factores de carácter objetivo, pero por sí mismos, como se ha analizado, no determinan que se pueda percibir el complemento de especial dedicación ${ }^{77}$, no es esto lo que persigue el legislador, ya que solo se consideran en la medida en que concurren esos otros factores a los que se ha hecho referencia que tienen un carácter subjetivo. En todo caso, no se trata de una retribución que percibe el sujeto por el mero hecho de desempeñar un puesto de trabajo realizando una determina jornada con un cierto horario, además, hay que tener en cuenta que no todos los sujetos van a percibir este complemento, podrán recibirlo, pero no hay que olvidar que es una parte variable de la retribución del personal de las Fuerzas Armadas.

\section{E1 carácter subjetivo del complemento de dedicación especial y su atribución}

Este complemento, tal y como se configura, constituye un derecho subjetivo del personal de las Fuerzas Armadas, de modo que su concesión y su cese en cuanto a la percepción del mismo debe ser individual ${ }^{78}$. Así, es indiferente que se realicen las

76 Vid.JANÉ ROCA, P. (2017: 164). Sin embargo, como se ha podido comprobar, en este caso no se trata de una retribución vinculada al empleo ostentado, ni tampoco al puesto de trabajo que ocupa el sujeto, es decir, no es el contenido del puesto el que determina que se perciba este complemento.

77 STSJ de Madrid (Sala de lo Contencioso-administrativo) de 31 de enero de 2012 (rec. 866/2010): "mediante él no se retribuye el puesto de trabajo, en cuanto a la penosidad intrínseca del mismo (exceso de horas de trabajo) sino el especial rendimiento, la actividad extraordinaria o iniciativa con que se desempeñe el destino, lo que no consta en autos por lo que el recurrente no tiene derecho a percibir cantidad alguna en concepto de complemento por dedicación especial".

78 SSTSJ de Murcia (Sala de lo Contencioso-administrativo) de 30 de marzo de 2001 (rec. 1243/1999), de 31 de julio de 2001 (rec. 1239/1999) y de 29 de septiembre de 2001 (rec. 92/2000): "La aplicación de este complemento en las Fuerzas Armadas, de manera análoga a como sucede con el de productividad, supone la evaluación diferenciada de cada militar por sus superiores jerárquicos". 
mismas funciones ${ }^{79}$ o se ocupen idénticos puestos de trabajo, ya que este concepto retributivo no se establece teniendo en cuenta las condiciones y características específicas del puesto, sino que está directamente relacionado "con la forma en que el militar desarrolla el puesto" en cuanto a "intensidad, eficacia y acierto" al desempeñar las funciones encomendadas ${ }^{80}$, valorándose, en todo caso, si en la prestación de servicios en los términos señalados se da ese "especial rendimiento", la "actividad extraordinaria", o la "iniciativa", a los que se ha hecho referencia ${ }^{81}$. En este sentido, dado su carácter individual, no existirá infracción del principio de igualdad en cuanto a la aplicación del complemento en los casos en los que se conceda a unos funcionarios y no a otros que ocupan puestos de trabajo similares, o realizan idéntico trabajo ${ }^{82}$. De este modo, "aunque se desempeñen idénticas funciones o se ocupen los mismos puestos de trabajo, es claro que siempre podrá valorar la Administración si en la prestación de servicios de cada funcionario, civil o militar, se da el "especial rendimiento", la "actividad extraordinaria" o la particular "iniciativa" a los que se refiere el precepto", de forma que el sujeto que reclame la percepción de este complemento deberá acreditar que ha realizado sus labores "con el mismo "rendimiento", "actividad extraordinaria" o "iniciativa" que los sujetos que lo perciben y que realizan las mismas funciones y ocupan un puesto idéntico ${ }^{83}$. Además, se trata de un complemento que no es consolidable, ni exige que su percepción deba ser periódica, ya que

79 Vid. SSTS (Sala de lo Contencioso-administrativo) de 8 y 24 noviembre 1995 (rec. 6723/1992 y rec. 5030/1992) de 19 enero 1996 (rec. 7054/1992) y de 26 de septiembre de 1996 (rec. cas. 413/1994): no procede "su aplicación por meros automatismos con base exclusivamente en una descripción de funciones".

$80 \mathrm{SAN}$ (Sala de lo Contencioso-administrativo) de 11 julio de 2002 (rec. 1179/2001).

81 SSTSJ Murcia (Sala de lo Contencioso-administrativo) de 30 de marzo de 2001 (rec. 1243/1999) y de 29 de abril de 2005 (rec. 593/02).

82 Vid. STSJ Madrid (Sala de lo Contencioso-administrativo) de 4 de mayo de 2006 (rec. 18/2003): "la naturaleza esencialmente subjetiva del complemento y las limitaciones económicas a las que se encuentra sujeto impiden apreciar cualquier infracción del principio de igualdad amparado por el art. 14 CE que los actores fundan en la atribución del complemento a los dos compañeros del recurrente pues no consta que la laboriosidad, iniciativa, etc. de los tres funcionarios destinados en esa dependencia sea la misma aunque realicen idénticas funciones" y STSJ de Andalucía, Sevilla (Sala de lo Contencioso-administrativo), de 16 de marzo de 2006 (rec. 1321/2000): “en atención a la naturaleza jurídica del complemento, ha de estimarse posible y correcto que determinados funcionarios que desempeñan puestos de trabajo de contenido idéntico puedan quedar diferenciados por tal retribución, tanto en su reconocimiento como en su importe, consecuencia de valorarse en ella el acierto, dedicación y entrega con que el funcionario acomete su trabajo, de tal modo que la simple existencia de unos funcionarios que perciben el complemento en cuestión no es razón bastante para que los restantes funcionarios que desempeñen puestos de trabajo similares, o aún idénticos, tengan derecho a su percepción".

83 Vid. SSTSJ de Murcia (Sala de lo Contencioso-administrativo) de 30 de marzo de 2001 (rec. 190/2000) y de 12 de julio de 2002 (rec. 186/2000). 
se atribuirá teniendo en cuenta la situación del funcionario en la que esté presente alguno de esos factores que han de valorarse ${ }^{84}$.

Así, dado ese carácter subjetivo del complemento de dedicación especial, la Administración, de forma discrecional, si bien, atendiendo a los factores señalados, podrá determinar la atribución del complemento en ciertas ocasiones y periodos ${ }^{85}$, al igual que su cese en cuanto a la percepción ${ }^{86}$. En todo caso, lo que no cabe es conceder este complemento en función del empleo, ni de la antigüedad ${ }^{87}$, ya sea en el empleo o en el destino, ni por la realización de guardias y servicios (apartado segundo de la OM 190/2001). Es cierto que la normativa que regula este complemento no señala expresamente que deba motivarse la concesión o el cese en la percepción de este complemento, si bien tampoco existe una exclusión al respecto. De todos modos, hay que recordar que el art. 35.i) de la Ley 39/2015, de 1 de octubre, del Procedimiento Administrativo Común de las Administraciones Públicas ${ }^{88}$, establece la necesidad de motivar los actos administrativos que obedecen a la actividad discrecional de la Ad-

84 Vid. STSJ de Andalucía, Sevilla (Sala de lo Contencioso-administrativo) de 8 de julio de 2008 (rec. 1114/2007). En este sentido, se ha cuestionado si el sujeto que percibe este tipo de complemento debe continuar recibiéndolo en los periodos en los que no realiza actividad profesional, como sucede en el caso en el que disfruta de permisos reglamentarios. Pues bien, hay que tener en cuenta que "es imprescindible cumplir con las condiciones requeridas para percibir el complemento de dedicación especial", de ahí que resulte "justificada la exclusión para su percepción” ya que en esos casos no se desarrolla una actividad "de la que quepa predicar el especial rendimiento o la dedicación extraordinaria" y ello al margen de que el personal de las Fuerzas Armadas tenga una disponibilidad permanente para el servicio. Cfr. STSJ de Galicia (Sala de lo Contencioso-administrativo) de 12 de abril de 2006 (rec. 739/2004).

85 STSJ de Andalucía, Sevilla (Sala de lo Contencioso-administrativo) de 16 de marzo de 2006 (rec. 1321/2000).

86 Atribución y cese que han de comunicarse al interesado mediante escrito del Jefe del Estado Mayor del Ejército correspondiente o por el Subsecretario de Defensa, en el ámbito de sus competencias, o por las Autoridades en quienes deleguen, y a la pagaduría correspondiente, haciendo constar el mes a partir del cual se le abonará o se cesará en la percepción, teniendo en cuenta lo establecido en el RD 1314/2005 y los citados criterios.

87 Vid. STSJ de Galicia (Sala de lo Contencioso-administrativo) de 20 de noviembre de 2002 (rec. 883/2000): "La antigüedad en el empleo puede y debe tenerse en cuenta para la fijación de otras retribuciones pero no para el complemento de dedicación especial"; SSTSJ de Andalucía, Sevilla (Sala de lo Contencioso-administrativo) de 1 de diciembre de 2005 (rec. 1318/2000): "El criterio de asignar el mencionado complemento de dedicación especial, excesivamente al Suboficial más antiguo - que es el aplicado por la Administración y se constata en los numerosos precedentes de casos similares- debe rechazarse, por cuanto no tiene una racional relación con la actividad extraordinaria, e iniciativa con que desempeñen el puesto de trabajo, tal y como se define esta retribución complementaria"; de 22 de diciembre de 2005 (rec. 1320/2000): "La mera antigüedad, aisladamente considerada, no es reveladora de dedicación especial definida por aquéllos conceptos indeterminados"; de 4 de septiembre de 2002 (rec. 245/ 1999); de 27 de noviembre de 2002 (rec. 1336/2000); STSJ de Murcia (Sala de lo Contencioso-administrativo) de 30 de mayo de 2003 (rec. 1196/2001) y STSJ de Galicia (Sala de lo Contencioso-administrativo) de 1 de septiembre de 2005 (rec. 412/2004).

88 BOE de 2 de octubre de 2015. 
ministración. Así, no es admisible una ausencia de motivación, tanto con respecto a la propia concesión como al cese en su percepción; el hecho de que se trate de un acto discrecional no significa que no deba motivarse, si así fuese la resolución sería nula ${ }^{89}$. Por tanto, aunque entre dentro de la potestad de organización de la Administración determinar a qué sujetos se va a atribuir el complemento de dedicación especial por su carácter subjetivo y aunque su decisión esté basada en los conceptos jurídicos indeterminados a los que se ha hecho referencia, esto no significa que la discrecionalidad técnica pueda conllevar discriminaciones, o que la asignación pueda ser arbitraria, o, teniendo en cuenta la indeterminación de esos conceptos, que pueda recurrir a otros criterios ajenos a los previstos por el legislador ${ }^{90}$.

En definitiva, la concreción de los funcionarios que van a percibir este complemento "debe de hacerse mediante una motivación adecuada y suficiente para evitar situaciones de desigualdad o agravio" "91. De este modo, el carácter subjetivo del complemento va a impedir que no se conceda a aquellos que lleven a cabo su labor con igual exigencia, con el mismo rendimiento o esfuerzo que otro sujeto que sí se le haya atribuido recurriendo para su justificación a factores ajenos a los establecidos normativamente para su asignación ${ }^{92}$. Además, hay que considerar que la Administración debe someterse al control jurisdiccional (art. 106.1 de la GE) y justificar su actuación partiendo de los criterios legalmente establecidos 93 ; "lo que implica el sometimiento de esta a los principios generales del Derecho, entre los que se cuenta el de interdicción de la arbitrariedad, art. 9.3 de la CE, y desde luego incurre en arbitrariedad la actuación que se convierte en fuente de decisiones que no resultan justificadas"94.

89 STSJ de Galicia (Sala de lo Contencioso-administrativo) de 20 de noviembre de 2002 (rec. 883/2000): "no se ha acreditado una distinción que conlleve aquel especial rendimiento, actividad extraordinaria y/o iniciativas en el desempeño del puesto de trabajo, ha de concluirse que se ha vulnerado la legalidad así como el principio de igualdad en la aplicación de la ley, lo que ha de llevar a la estimación del recurso en el sentido de decretar la nulidad de la resolución recurrida".

90 STSJ de Andalucía, Sevilla (Sala de lo Contencioso-administrativo) de 1 de diciembre de 2005 (rec. 1318/2000): "La asignación de este complemento por razón de la antigüedad del Suboficial, se aparta claramente de la disposición legal en que se fundamenta, y por tanto la exclusión supone la discriminación de los Suboficiales con menor antigüedad".

91 SSTSJ de Andalucía, Sevilla (Sala de lo Contencioso-administrativo) de 6 de marzo de 2002 (rec. 192/1999) y de 1 de diciembre de 2005 (rec 1318/2000).

92 STSJ de Andalucía, Sevilla (Sala de lo Contencioso-administrativo) de 1 de diciembre de 2005 (rec. 1318/2000).

93 STSJ de Galicia (Sala de lo Contencioso-administrativo) de 20 de noviembre de 2002 (rec. $883 / 2000)$.

94 STSJ de Andalucía, Sevilla (Sala de lo Contencioso-administrativo) de 6 de marzo de 2002 (rec. 192/1999). 


\section{La incidencia de determinados factores en su percepción y/o su cuantía}

Sin embargo, también hay que tener en cuenta que, en la práctica, se han venido planteando problemas al respecto. En concreto, a pesar de retribuir aspectos subjetivos, el empleo ha tenido relevancia a la hora de determinar la cuantía del complemento, de hecho en la regulación previa a la prevista en la actualidad en el RD 1314/2005, dicha cuantía se refería a un porcentaje del importe del complemento de empleo. Por esta razón, partiendo de lo anterior, el complemento se ha vinculado, más que a las condiciones y criterios señalados, al concreto empleo ${ }^{95}$. De este modo, aunque existe un complemento de empleo, el complemento de dedicación especial se ha venido percibiendo, a su vez, como un complemento de este. Si bien, al suprimir la referencia al mencionado porcentaje en la regulación vigente se ha favorecido la eliminación de la tendencia a vincularlo al empleo en la práctica; vinculación que, como se ha señalado, no es admisible ${ }^{96}$. En el mismo sentido, el destino ha sido otro elemento que en algunos casos se ha tenido en cuenta a la hora de establecer la citada cuantía, en concreto, para el personal del Ejército de Tierra destinado en Navarra y País Vasco $^{97}$, retribuyendo de esa forma una condición objetiva, en lugar de las condiciones subjetivas que determinan que el sujeto deba percibir el complemento de dedicación especial. Así, en la práctica, "a través de un complemento llamado a retribuir condiciones "subjetivas" del personal militar se está retribuyendo una condición objetiva de los distintos puestos desempeñados por el mismo (...) y no dependiente

95 Vid. OBSERVATORIO DE LA VIDA MILITAR (2017: 18 y 112-113): "el porcentaje mayor de los que no perciben este complemento se encuentra entre los empleos de subteniente a soldado".

96 Vid. CANTERA DE CASTRO, Z., Comisión de Defensa de 26 de abril de 2017, para informar sobre temas relativos al Proyecto de Ley de Presupuestos Generales del Estado, 2017, en https://www.youtube.com/watch?$\mathrm{v}=8 \mathrm{QmBaIVXZR} 8$

97 STSJ de Navarra (Sala de lo Contencioso-administrativo) de 9 de enero de 2019 (rec. 177/2018): "A partir de octubre de 2001, para paliar la derogación formal del instrumento por el que se estableció una gratificación por servicios a todo el personal de las Fuerzas armadas destinado en País Vasco o Navarra, el Ejército de Tierra arbitró un procedimiento dentro del marco normativo que permitiera el mantenimiento de las retribuciones anteriores a octubre de 2001 a cargo del complemento de dedicación especial, así se dictó Norma Particular de Aplicación del complemento de dedicación especial en el País Vasco y Navarra para el Ejército de Tierra vigente desde el 1 de enero de 2003 hasta el año 2007 en la que se establecía los porcentajes que sobre el complemento de empleo percibiría el personal destinado en País Vasco y Navarra, desde octubre de 2007 se ha venido abonado por el Ejército de tierra a cargo del complemento de dedicación especial una cuantía fija al personal destinado en unidades radicadas en Navarra y País Vasco (...). Por contra el Ejército del Aire no lo hizo así, y en cualquier caso, la realidad es que miembros del Ejército de Tierra destinados en Navarra y País Vasco siguen cobrando en concepto de complemento de dedicación especial superiores cuantías". 
de las condiciones "individuales" (rendimiento, iniciativa, actividad, etc.) de quienes las ocupan"98.

También se ha planteado hasta qué punto está justificado que en ocasiones se haya venido percibiendo todos los meses, con carácter fijo o rotatorio, durante un determinado número de meses, o en meses alternos, teniendo en cuenta las disponibilidades presupuestarias. En este sentido, el problema no es tanto si se cobra de forma ininterrumpida o si existe una rotación a la hora de percibirlo, sino si, teniendo en cuenta los factores que han de concurrir, todos los sujetos que lo perciben son realmente acreedores del mismo; de forma que, por razones presupuestarias, la fórmula a la que se acude "se acomoda razonablemente al derecho a la igualdad en la aplicación de la Ley o norma jurídica (art. 14 de la CE)"99 considerando que los sujetos merecen percibirlo; lo que no sería admisible en caso contrario ${ }^{100}$.

Cuestión distinta es si cabe privar de este complemento a quienes tengan reducida su jornada, con el fin de conciliar su vida personal, familiar y profesional, en los términos que se establecen en la Orden DEF/253/2015, de 9 de febrero, por la que se regula el régimen de vacaciones, permisos, reducciones de jornada y licencias de los miembros de las Fuerzas Armadas ${ }^{101}$ (ODEF 253/2015). En la actualidad, el legislador deja clara la compatibilidad de la reducción de jornada con la percepción del complemento de dedicación especial cuando corresponda de acuerdo con lo previsto en el art. 3.4 del RD 1314/2015 (art. 22.5 de la ODEF 253/2015). Es cierto, por una parte, que, salvo en el caso de reducción de jornada por enfermedad muy grave, estos sujetos ven reducidas proporcionalmente sus retribuciones, pero esto no va a implicar que se les deba privar del complemento; y, por otra, que lo habitual es que queden exonerados de guardias, servicios, maniobras o actividades análogas, con excepciones en las que la exoneración queda condicionada al hecho de que las necesidades

98 Cfr. SSTSJ Navarra (Sala de lo Contencioso-administrativo) de 9 de enero de 2019 (rec. 177/2018), de 26 de octubre de 2018 (rec. 83/2018), y de 30 de noviembre de 2017 (rec. 21/2017).

99 STSJ de Murcia (Sala de lo Contencioso-administrativo) de 25 de mayo de 2001 (rec. 1241/1999): "la Administración está reconociendo, en el citado informe, que todos los suboficiales del buque B.S.R. "Neptuno" son acreedores a la percepción del complemento de dedicación especial; ahora bien, también es cierto que las cuantías del complemento de dedicación especial son determinadas por el Ministerio de Defensa dentro de los créditos que se asignen para esta finalidad (artículo 4.4 del Reglamento de Retribuciones y Leyes de Presupuestos Generales del Estado para cada año), razón por la cual, en el buque "Neptuno" no pueden los suboficiales percibir todos los meses, ininterrumpidamente, el complemento de dedicación especial; y la fórmula a la que se acude entonces para su abono (rotación mensual) se acomoda razonablemente al derecho a la igualdad en la aplicación de la Ley o norma jurídica (artículo 14 de la CE), pues todos los suboficiales embarcados en ese buque merecen percibirlo".

100 STSJ de Murcia (Sala de lo Contencioso-administrativo) de 31 de julio de 2001 (rec. 1239/1999). En cuanto al reparto y la falta de disponibilidad presupuestaria, vid. SSTC 117/2004, de 12 de julio y 76/2005, de 4 de abril.

101 BOE de 18 de febrero de 2015. 
del servicio lo permitan. Precisamente, por lo que aquí interesa, en la práctica, se ha podido comprobar cómo en las resoluciones se ha invocado la no realización de guardias, servicios, maniobras o actividades análogas como razón para privar del complemento a los sujetos. Ahora bien, esta exoneración no puede determinar que los sujetos se vean privados de este complemento, ya que este, como se ha señalado, no puede concederse por la realización de guardias y servicios ${ }^{102}$.

\section{LA GRATIFICACIÓN POR SERVICIOS EXTRAORDINARIOS}

La gratificación por servicios extraordinarios del personal de las Fuerzas Armadas ya estaba prevista en el art. 5.3.3 del RD 662/2001, y, en la actualidad, se contempla en los mismos términos en el art. 3.5 del RD 1314/2005. En general, como se puede comprobar, esta gratificación solo se establece para servicios extraordinarios que han de llevarse a cabo fuera de la jornada normal, por tanto, no para cualquier labor; por ello, se trata de una gratificación que tiene carácter excepcional, que no puede ser fija en su cuantía, ni puede devengarse de forma periódica. De este modo, se puede afirmar que el legislador reproduce lo previsto en el art. 23.3. d) de la LMRFP, que en la actualidad se recoge en el art. 24.d) del EBEP; si bien, en el caso del personal de las Fuerzas Armadas se concede por el Ministerio de Defensa en las cuantías que este determine.

Como se viene señalando, el art. 25 de la LOFFAA indica que el sistema retributivo de este colectivo será el de los funcionarios civiles de la Administración General del Estado, y establece su adaptación "a las características de las Fuerzas Armadas, a las peculiaridades de la carrera militar y a la singularidad de los cometidos y funciones que tienen asignados". En este sentido, al reproducir lo establecido en la citada norma se podría pensar que la regulación prevista para los funcionarios civiles se aplica a los miembros de las Fuerzas Armadas sin ningún tipo de adaptación. Sin embargo, hay que considerar que por Orden 853/2002, de 10 de abril ${ }^{103}$, el Ministro delegó la referida competencia en el Subsecretario de Defensa, quien dictó la Instrucción 74/2004, de 13 de abril, por la que se aprueban las normas a seguir para el abono de gratificaciones por servicios extraordinarios al personal militar y civil funcionario (Instrucción 74/2004). En concreto, entre otros aspectos, en la misma se hace referencia al concepto de gratificación por servicios extraordinarios

102 Vid. STSJ de Madrid (Sala de lo Contencioso-administrativo) de 25 de marzo de 2013 (rec. 1184/2009): "siendo compatible en abstracto la reducción de jornada con la percepción del complemento de dedicación especial y no ajustándose a la regulación del citado complemento la razón invocada en la resolución impugnada para denegar su asignación a la actora -la no realización por la misma de guardias y servicios-, sólo cabe la anulación de las resoluciones que constituyen el objeto del presente recurso".

103 BOE de 19 de abril de 2002. 
y a las limitaciones relativas a su aplicación. En este caso, por lo que aquí interesa, es importante tener en cuenta que para percibir esta gratificación deben darse dos condiciones, al igual que para los funcionarios civiles de la Administración General del Estado, de un lado, debe tratarse de servicios que se realicen fuera de la jornada normal de trabajo; y, de otro, esos servicios deben ser extraordinarios (norma tercera de la Instrucción 74/2004). Ahora bien, aspectos como la disponibilidad permanente para el servicio, y las propias funciones que tiene encomendadas el personal de las Fuerzas Armadas, han determinado que a este colectivo se le aplique una regulación específica que difiere de la prevista para esos funcionarios civiles; aun partiendo de unas condiciones que, en un primer momento, pueden parecer iguales. Por esta razón, para conocer si el citado personal cumple las condiciones necesarias para obtener esta gratificación es fundamental determinar para este concreto colectivo, en primer lugar, qué se entiende por realizar servicios fuera de la mencionada jornada normal de trabajo, y, en segundo lugar, cuáles de esos servicios que se llevan a cabo fuera de esa jornada se consideran extraordinarios.

\section{La necesidad de que los servicios se realicen fuera de la jornada normal de trabajo}

El hecho de que los servicios se deban realizar fuera de la jornada normal de trabajo no significa que se pueda asimilar al concepto de horas extraordinarias previsto en el art. 35 del Real Decreto Legislativo 2/2015, de 23 de octubre, por el que se aprueba el texto refundido del Estatuto de los Trabajadores ${ }^{104}$, ni, desde luego, que se pueda aplicar de algún modo su regulación ${ }^{105}$, ni, como se verá, que por llevarse a cabo fuera de esa jornada se consideren servicios extraordinarios. El problema que se puede plantear con respecto a la necesidad de que se deben llevar a cabo fuera de la citada jornada está relacionado con la disponibilidad para el servicio, ya que se trata de una disponibilidad permanente, tal y como se establece en el art. 20 del RDRROO y en el art. 22.1 de la LOFFAA, y se podría pensar que esa disponibilidad permanente puede dificultar el establecimiento de una jornada y la propia determinación de qué se considera o no servicio extraordinario. Sin embargo, hay que tener en cuenta que el legislador, como se puede apreciar en el art. 22.2 de la LOFFAA, establece que la jornada de trabajo de los militares será la del personal al servicio de la Administración General del Estado, a la vez que indica que el régimen de horario se debe adaptar a las necesidades operativas, a las derivadas del funcionamiento de las unidades y de la prestación de guardias y servicios, considerando en todo caso la mencionada disponibilidad permanente y la necesidad de conciliar la

104 BOE de 24 de octubre de 2015.

105 Vid. STSJ de Castilla y León, Valladolid (Sala de lo Contencioso-administrativo) de 23 de mayo de 2013 (rec. 630/2009). 
vida profesional, personal y familiar. Aspectos que, en la actualidad, se contemplan en la ODEF 2016.

Lo cierto es que en la ODEF 2016 no se hace referencia como tal a la jornada normal de trabajo, sino que, como se ha indicado, en la misma se regulan distintos tipos de jornada (la jornada general de trabajo, la jornada especial, que conlleva la obligación de realizar una jornada de trabajo superior a la jornada general, y la jornada de verano), y para estos se contemplan diferentes horarios y, en determinados supuestos, por necesidades del servicio, la posibilidad de incrementar el horario de trabajo (arts. 6 y 9); así como la de introducir adaptaciones por diferentes razones (art. 5). Por tanto, cuando se hace referencia a la realización de servicios fuera de la jornada normal de trabajo hay que partir de los distintos tipos de jornadas, de los horarios establecidos, y, en concreto, de la probable prolongación de la jornada en cuestión. Lo que conlleva que por las citadas "necesidades del servicio, ya sean operativas o de funcionamiento de la unidad", se incremente "de forma ocasional el horario habitual de trabajo"; horario que, como se ha señalado, varía dependiendo de los citados tipos de jornada y "determina la hora de inicio y fin de las actividades diarias en el destino" (art. 3 aparts. 3 y 4 ODEF 2016).

\section{Los servicios extraordinarios como actividades no exclusivamente militares}

Ahora bien, cuando el legislador contempla las mencionadas gratificaciones para el personal de las Fuerzas Armadas lo hace no para cualquier servicio que se realice fuera de la jornada normal de trabajo, sino solo para "servicios extraordinarios". Además, no se puede interpretar que todos los servicios que se realizan fuera de dicha jornada lo son. En este sentido, hay que tener en cuenta que la citada norma tercera de la Instrucción 74/2004 hace referencia a los servicios extraordinarios en términos negativos, de forma que señala que no se incluyen como tales "la realización de guardias o servicios, u otros de naturaleza similar". Así, se ha considerado que no son servicios extraordinarios las "actividades inherentes al servicio o función desempeñado"106; de modo que "no cabe retribuir como servicios extraordinarios aquellas actividades que sean puramente militares y como consecuencia del desarrollo propio del destino ocupado y/o de la profesión militar"107 y que se puedan

106 Como es el caso de la "participación en maniobras militares, así como el resto de ejercicios, actividades y operaciones propias de la función militar", vid. SSTSJ Madrid (Sala de lo Contencioso-administrativo) de 21 de febrero de 2008 (rec. 222/07), de 30 de septiembre de 2011 (re. 639/2011) y de 31 de enero de 2012 (rec. 866/2010): "Las funciones desempeñadas por el recurrente no son servicios extraordinarios fuera de la jornada normal de trabajo, sino que son funciones propias del cargo del recurrente".

107 STSJ de Castilla y León, Valladolid (Sala de lo Contencioso-administrativo) de 23 de mayo de 2013 (rec. 630/2009). 
incardinar, como se ha señalado, en las citadas guardias, servicios u otros de similar naturaleza ${ }^{108}$, por lo que, a sensu contrario, las actividades que no sean inherentes al servicio o función, las que no sean exclusivamente militares, se considerarán servicios extraordinarios ${ }^{109}$.

No obstante, tampoco se califican como servicios extraordinarios, como señala la mencionada norma tercera de la Instrucción 74/2004, "los trabajos remunerados por algún otro concepto retributivo". Con respecto a estos últimos hay que recordar, como se ha indicado, que el especial rendimiento, la actividad extraordinaria o la iniciativa con la que se desempeñe el destino se retribuyen con el complemento de dedicación especial en los términos señalados. De forma que quedarían excluidos

108 En cuanto a los citados servicios "de naturaleza similar", es posible señalar cómo se han considerado como tales, y, por tanto, no son servicios extraordinarios, en concreto, para el Ejército de Tierra, los desfiles, incluidos los procesionales; tiro e instrucción nocturna y lo que implique instrucción adiestramiento de Unidades, Centros u Organismos (UCO,s); asistencia a actos protocolarios militares; activación de UCO,s; servicios de mantenimiento en UCO,s y administración de órganos de acción social, excepto casos extraordinarios de reparaciones de averías graves o de liquidaciones urgentes de cierres de ejercicio económico, etc; jornadas de puertas abiertas; asistencia a exposiciones, conferencias y seminarios; servicios de seguridad en general; asistencia a grupos de trabajo; cursos en UCO,s; tomas de posesión de Mando; asistencias a Actos Institucionales (Juras de Bandera, conmemoraciones, aniversarios, celebraciones, conciertos, Patronas/os, etc); acciones de revisión o mantenimiento diario o periódico de Instalaciones; operaciones militares en TN o en el exterior, incluidas las acciones previas y posteriores a las mismas; acciones operativas y logísticas de las UCO,s; jornadas de instrucción continuada o diurna de las UCO,s (apartado 5.5.2 Instrucción Técnica 07/10, abril 2010 (IT 07/2010), en http://www.as-fas.es/zSociosForo/Normativa/IT\%200007-2010\%20Gratificaciones $\% 20$ svs $\% 20$ extraordinarios.pdf).

109 Así, se ha entiendo que son servicios extraordinarios, de acuerdo con lo establecido en el apartado 5.5.1 IT 07/2010 con respecto al personal del Ejército de Tierra, actividades tales como la participación en Tribunales y Secretarías de exámenes; conductores y escoltas especiales de Autoridades en Actos Oficiales; asistencia a extinciones de incendios $u$ otros desastres naturales siempre fuera de la campaña anual contra incendio y fuera de los Campos de Tiro e Instrucciones militares; colaboraciones y asistencias de usuarios militares en activo o en situación de reserva, en el desarrollo eventual de funciones de profesor o monitor en actividades recreativas, deportivas o culturales en los Centros Deportivos Socioculturales Militares del Ejército de Tierra; colaboraciones y asistencias de usuarios militares en activo o en situación de reserva en Grupos de Estudio convocados por el Mando de Adiestramiento y Doctrina; realización de liquidaciones, inventarios y memorias anuales que por su urgencia debidamente justificada, originen su ejecución en plazos extraordinarios; componentes de Juntas de Evaluación para ascenso y acceso a Tropa Permanente de Militares de Tropa, Secretarías de exámenes para ingreso en las distintas Escalas, Tribunales y Órganos de apoyo a concurso-oposición, cambio de especialidad en la Academia General Militar, Academia General Básica de Suboficiales, y Academia de Logística y operaciones contables; servicios generales para facilitar la acción social y asistencia al personal del Ejército, que carezcan de otra vía de compensación; cometidos de Jefe de escoltas, escoltas y conductores del Jefe del Estado Mayor del Ejército de Tierra, y servicios extraordinarios en apoyo de dicha Autoridad; servicios de apoyos previos y posteriores a la realización de actos protocolarios militares; carga y descarga de material de nueva adquisición, etc; pruebas de equipos y materiales. Programas de adquisición; acciones de revisión o mantenimiento urgente de instalaciones, ante averías graves. Si bien, este listado de servicios no es cerrado ya que también se hace referencia a "otras actividades similares"; lo que permite incluir otros servicios que no sean puramente militares. 
todos ellos de la gratificación por servicios extraordinarios. Es cierto que se podría pensar que en los casos en los que se desarrolla una jornada superior a la prevista podría existir cierta dificultad a la hora de determinar el concepto retributivo por el que se remuneran los servicios, sin embargo, hay que tener en cuenta que el legislador hace referencia a servicios extraordinarios, es decir, de carácter excepcional, por ello quedan al margen de su consideración como tal, los desarrollados con una cierta frecuencia fuera de la jornada laboral, de forma que se retribuyen mediante el complemento de dedicación especial (norma quinta de la Instrucción 74/2004) ${ }^{110}$. Al igual que tampoco se puede hacer referencia a servicios extraordinarios en los casos en los que se consideran las especiales condiciones en que la unidad de destino desarrolla su actividad, y, en concreto, las particulares condiciones de responsabilidad, preparación técnica, peligrosidad y penosidad del puesto, ya que se retribuyen con el componente singular del complemento específico.

\section{VALORACIONES FINALES}

Aunque al personal de las Fuerzas Armadas se le aplica el sistema retributivo de los funcionarios civiles de la Administración General del Estado con las adaptaciones a las que se ha hecho referencia, se puede constatar que no es posible afirmar que exista una verdadera equiparación a partir de esas adaptaciones. Los criterios que se contemplan en la regulación prevista para el personal de las Fuerzas Armadas para cada uno de los complementos retributivos no siempre son los mismos. De hecho, se puede observar cómo el empleo predomina claramente en el ámbito militar dejando al margen criterios objetivos que se aplican en el civil, lo que pone de manifiesto, a su vez, cómo el fundamento y la finalidad de estos complementos varían en algunos casos con respecto a los que se contemplan para los citados funcionarios civiles, tal y como se ha podido constatar al analizar el complemento de empleo y el componente general del complemento específico, con las consecuencias que ello conlleva. No sucede lo mismo en cuanto al componente singular del complemento específico, aunque indirectamente, si se tiene en cuenta la responsabilidad, se vincule al empleo ${ }^{111}$.

Como se ha podido comprobar, respecto al complemento de dedicación especial, no siempre se consideran única y exclusivamente factores de carácter subjetivo sino que a estos se añaden otros de carácter objetivo que condicionan la percepción del mismo y/o su cuantía, por lo que cabría plantearse hasta qué punto se ajusta a su

110 Teniendo en cuenta los factores a los que se ha hecho referencia con respecto a este complemento.

11 De todos modos, sería necesario considerar los nuevos requerimientos de los diferentes puestos de trabajo y adaptar los importes de este componente, vid. OBSERVATORIO DE LA VIDA MILITAR (2017: 129): "puestos de trabajo en los que cada vez adquiere más valor la preparación técnica y la responsabilidad". 
verdadera finalidad ${ }^{112}$. En este sentido, deberían concretarse en mayor medida estos criterios con el fin de que puedan ser identificados claramente por los miembros de las Fuerzas Armadas ${ }^{113}$, evitando recurrir a factores que no correspondan a dicha finalidad $^{114}$. Pero, además, esta no es la única disfunción que se produce, ya que, como se ha indicado, no cabe conceder el complemento de dedicación especial por la realización de guardias y servicios, a pesar de que precisamente supongan una mayor dedicación, y, además, tampoco es posible compensarlos con una gratificación por servicios extraordinarios porque no se consideran como tales. Lo que, a su vez, pone de manifiesto que no existe una verdadera proporcionalidad entre las horas prestadas y las retribuidas o compensadas con descanso, como en la práctica sucede, sobre todo si se tiene en cuenta que, aunque en el art. 11.4 de la ODEF 2016 se contempla la compensación con descanso de guardias, servicios, instrucciones continuadas, ejercicios o actividades análogas, existe un límite máximo de diez días de descanso anuales ${ }^{115}$; lo que supone que si exceden de esos días no se van a retribuir, ni se van a compensar con días de descanso, como tampoco se consideran a efectos retributivos el trabajo nocturno, o en días festivos. En los casos en los que se superen esos diez días, si no son compensados con descanso, debería concederse a este personal el complemento de dedicación especial en el mes en el que esto suceda, valorando asimismo el trabajo nocturno y el realizado en días festivos, ya que el hecho de que este personal tenga disponibilidad permanente, sin duda, conlleva restricciones que le afectan, pero esto no puede implicar que ese exceso de horas no sea compensado o retribuido ${ }^{116}$.

112 Vid. Dictamen emitido por la Comisión de Defensa el día 21 de febrero de 2018, en relación al Informe anual de 2016 del Observatorio de la Vida Militar, Boletín Oficial de las Cortes Generales del Congreso de los diputados de 15 de marzo de 2018 (en http://www.observatoriodelavidamilitar.es/doc/ Dictamen_Comision_Defensa_Informe_Anual_2016.pdf), en el que se insta al gobierno a revisar algunos conceptos retributivos.

113 Vid. Dictamen emitido por la Comisión de Defensa el día 21 de febrero de 2018, op. cit.

114 Vid. OBSERVATORIO DE LA VIDA MILITAR (2017: 193): de hecho "se considera que la asignación del complemento de dedicación especial se retribuye eminentemente por razón del empleo desempeñado".

115 Límite que se mantiene a pesar de que la Orden DEF/110/2019, de 8 de febrero (BOE de 9 de febrero de 2019) ha modificado la ODEF 2016.

116 En todo caso, con independencia de lo señalado, deberían actualizarse las retribuciones, sin que por ello se deje de reflejar las peculiaridades propias de la actividad de este colectivo, evitando que se produzca un tratamiento desigual, con respecto a otros funcionarios públicos. 


\section{BIBLIOGRAFÍA}

BAÑÓN MARTÍNEZ, R., "La racionalidad de las política de remuneraciones y el diseño de la organización militar española", en Revista Internacional de Sociología, núm. 43 (1985), pp. 269-303.

CANTERA DE CASTRO, Z., Comisión de Defensa de 26 de abril de 2017, para informar sobre temas relativos al Proyecto de Ley de Presupuestos Generales del Estado, 2017, en https://www.youtube.com/watch?v=8QmBaIVXZR8

CASTILLO BLANCO, F.A. "Luces y sobras del complemento de productividad ¿un concepto retributivo inaplicado?", en Fusticia Administrativa: Revista de Derecho Administrativo, núm. 8 (2000), pp. 5-24.

CASTILLO BLANCO, F.A., El sistema retributivo en la función pública española, Marcial Pons, Madrid, 2002.

CASTILLO BLANCO, F.A., "Los derechos retributivos de los empleados públicos", en SÁNCHEZ MORÓN, M. (dir.), Comentarios a la Ley del Estatuto Básico del Empleado Público, Lex Nova, Valladolid, 2008.

JANÉ ROCA, P., La evaluación de la productividad del empleado público: El caso de la Administración de la Generalitat de Cataluña (2009-2014), Universidad de Barcelona, Barcelona, 2017, en www.tesisenred.net/handle/10803/457563\#page=1

LORENZO DE MEMBIELA, J.B., Retribuciones de los Funcionarios Públicos, Aranzadi Thomson Reuters, Cizur Menor, 2010.

OBSERVATORIO DE LA VIDA MILITAR, Memoria Informe año 2016, 2017, en http://www.observatoriodelavidamilitar.es/informes.html

ORTUÑO NAVALÓN, M.C. y MANZANA LAGUARDA, R.S., Las retribuciones de los empleados públicos. Estatuto Básico del Empleado Público, Tirant lo Blanch, Valencia, 2008.

PALOMAR OLMEDA, A., "Los límites jurisprudenciales sobre la fijación del complemento de productividad de los funcionarios: a propósito de las últimas sentencias sobre la materia”, en Actualidad Furídica Aranzadi, núm. 662 (2005), BIB $2005 \backslash 686$.

Palomar OlmedA, A., Derecho de la Función Pública. Régimen jurídico de los funcionarios públicos, Dykinson, S.L., Madrid, 2016.

SALVADOR CENTELLES, V., "La reforma del sistema retributivo del personal de las Fuerzas Armadas", en Presupuesto y Gasto Público, núm. 41 (2005), pp. 383-404. 